\title{
Archiv
}

f ü $r$

\section{pathologisehe Anatomie und Physiologie}

und für

\section{klinische Medicin.}

Bd. LXXVIII. (Siebente Folge Bd. VIII.) Hft. 3.

\section{XVIII.}

\section{Das japanische Fluss- oder Ueberseliwemmungsfieber, eine acute Infectionskrankheit.}

\author{
Von Prof. E. Baelz, Tokio, Japan, \\ in Verbindung mit
}

Stud. med. Kawakami.

\section{Einleitung.}

Am Westabhange der grossen Gebirgskette, welche die japanische Hauptinsel in zwei Hälften theilt, tritt jeden Sommer zur Zeit der grössten Hitze an drei Orten eine endemische Krankheit auf, die durch das Räthselhafte ihrer Entstehung und durch ihre Gefährlichkeit ein Gegenstand des Schreckens für die Bewohner der betroffenen Bezirke geworden ist. Diese Bezirke liegen alle in der nächsten Umgebung dreier grösserer Flüsse, nehmlich des Shinanogawa ${ }^{1}$ ) (des grössten Stromes Japans), eines seiner Nebenflüsse, und des weiter nördlich, in der Provinz Akita fliessenden Oomonogawa.

In jedem einzelnen Falle ist das Gebiet ein beschränktes, scharf umschriebenes, durch die Frühjabrsüberscbwemmungen be-

') Aussprache der japaniscben Worte: Vocale wie im Deutschen, Consonanten wie im Englischen. - Shinano ist der Name einer japanischen Provinz, Kawa, in Zusammensetzungen gawa, bedeutet Fluss.

Arohiv f. pathol. Anat. Bd. LXXVIII. Hft. 3. 
stimmtes. Nur wo der ausgetretene Fluss hingelangt, zeigt sich die Krankheit. Wenn demgemäss die Ueberschwemmung die nothwendige Voraussetzung der Krankheit ist, so ist letztere durchaus nicht die nothwendige Folge der Ueberschwemmung; denn es giebt am Shinanogawa selbst zahlreiche Flächen, die jedes Jahr unter Wasser stehen, ohne dass die Krankheit auftritt, und vollends an der Ostküste, wo doch grosse Ueberschwemmungen in den unteren Flussläufen die Regel bilden, ist die Krankheit ganz unbekannt. Es muss also noch eine locale Ursache vorhanden sein, um den Krankheitsstoff wirksam zu machen.

Dieses weitere Agens im parasitären Gebiete zu suchen, lag um so näher, als die Krankheit inren Ausgang von einer Art Wunde zu nehmen scheint, und als fast nur solche Leute, welche sich Verletzungen durch kleine Thiere besonders aussetzen, nehmlich Schnitter, befallen werden. Der Name Tsutsuga mushi, unter welchem die Krankheit wenigstens gerüchtweise fast allen Japanern bekannt ist, deutet auf eine solche Auffassung bin. In früheren Zeiten sollen nehmlich Reisende häufig unterwegs von einem schrecklichen Thiere gebissen worden und daher die Sitte entstanden sein, dass man am Ziel der Reise angekommen, den Seiuigen berichtete, man sei Tsutsuga nashi, d. h. ohne verletzt zu sein, angelangt. In China soll etwas Aehnliches bestanden und der Gebrauch von da sich auf Japan übertragen haben. Der Name Tsutsuga mushi ist auf unsere Krankheit transferirt worden, obne dass man ursprünglich unter Mushi ein bestimmtes Thier verstanden hätte. Mushi ist das gemeinschaftliche japanische Wort für Insecten, Milben und Würmer, oder eigentlich überhaupt für alles, was da an kleinen Geschöpfen kreucht und fleucht, und dadurch ist eine grosse Verwirung in den Ansichten entstanden. Die früheren Aerzte behaupteten in der Wunde einen Wurm gefunden zu haben, der sich in der Wärme bewege, und sie dernonstrirten ihn den Kranken selbst, wie ich wiederholt hörte. Das Ganze war aber nur ein Kunststückchen, das die Aerzte aufführten, um ihre Unwissenheit in den Augen des Publicums zu maskiren und sich ein Wesen zu geben, was beim japanischen Arzt alter Schule noch heute ebenso wichtig ist, als bei unseren Charlatanen im Mittelalter. Sie befestigten nehmlich nach Herrn Kawakami's Angabe an der Unterfläche des Pllasters, das sie auf die Wunde klebten, einen steifen Faden oder dergleichen. 
Beim Abnebmen des Pflasters blieb natürlich der Faden oder das Haar daran hängen und wenn man ibn in die Nähe heisser Kohlen oder einer Kerze brachte, fing er an sich zu bewegen and zu krümmen, - ein Beweis, dass der Arzt den schädlichen Wurm wirklich entfernt batte. Noch vor 4 Jabren bebauptete ein Arzt, welcher in der Nähe von Kurodzu practicirte, den Wurm zejgen zu können. Allmählich aber kamen doch Aerzte, welche sich wenigstens etwas mit abendländischer Medicin befasst hatten und einigernaassen zu untersuchen verstanden. Diese konnten den Wurm nicht finden, wohl aber fanden sie öfters auf dem Körper der Kranken eine kleine rothe Milbe (Akamushi, rothe Mushi), und vermutheten, dass diese die Krankheit hervorbringe. Diese Milbe wurde nach Tokio gebracht und stellte sich als ein Leptus autumnalis oder als naher Verwandter desselben heraus (vgl. unten).

An manchen Orten wurde die Krankheit auch als Shimamushi (d. h. Inselmushi) bezeichnet, weil eben Inseln und frisches Alluvium die Hauptheerde bilden. Andererseits hatte sich in Tokio unter den Aerzten die Meinung verbreitet, das Ganze sei nur einfach ein missverstandener oder schlecht beobachteter Typhus, oder gar Pest. Etwas Genaueres aber wurde nie bekannt, bis Herr Stud. med. Kawakami die Sommerferien 1877 dazu benutzte, die in der Nähe seiner Heimat gelegenen betroffenen Ortschaften zu besuchen und die Krankheit zu beobachten. Seine Mittheilungen bei seiner Rückkehr nach Tokio waren so interessant, dass ich beschloss, den Monat August selbst an jenen Orten zuzubringen und mit Herrn Kawakami das offenbar in der Pathologie bisher unbekannte Leiden zu studiren. Das kais. japaniscbe Gesundheitsamt gab uns eine Empfehlung an den Gouverneur der Provinz, und dieser stellte eine kleine Summe und einen Tempel als Hospitalraum zur Verfügung.

Das Resultat unserer Untersuchungen ist im Folgenden zusammengefasst.

Ehe indessen zur Besprechung der Krankheit selbst übergegangen wird, ist es nothwendig, die localen Verhältnisse, wie jch sie vorfand, kurz zu schildern, indem dadurch das Verständniss sehr erleichtert wird.

Der Shinanogawa ${ }^{1}$ ) hat, wie die meisten japanischen Flüsse,

1) Vgl. Stieler's Hand-Atlas, der eine sehr richtige Darstellung der geographischen Verhältnisse giebt. 
einen relativ langen Oberlauf durch Gebirge, mit starkem Fall und vielen Stromschnellen, und einen relativ sehr kurzen Mittel- und Unterlauf. Auch alle seine Nebenflüsse sind bis zu ihrer Einmündung eigentlich nur Gebirgsbäche. Dieses Verhalten begünstigt natürlich grosse Frühjahrsüberschwemmungen, wobei das Klima wirksam mithilft, das in seiner Art wohl fast einzig dasteht durch die Gegensätze zwischen Sommer und Winter. Unter $37^{\circ}$ n. B. gelegen, zeigt das untere Shinanogawathal, kaum über die Meeresfläche erhaben (Durchschnittsbarometerstand in Kurodzu in $\mathbf{3}$ Wochen $759 \mathrm{Mm}$.), im Winter eine Schneemenge, wie sie selbst in kalten Gegenden Deutschlands fast unerbört ist. Fast regelmässig fällt der Schnee bei Nagaoka ${ }^{1}$ ), wo ich meine Beobachtungen machte, 6 bis 10 Fuss tief, so dass alle Häuser, um überhaupt im Winter eine Communication zu ermöglichen, mit Arcaden versehen sind. Im Sommer dagegen erreicht die Temperatur Mittags meist $30^{\circ}$, und sinkt selbst bei Nacht selten unter $\mathbf{2 2}^{\circ}$, daher Palmen und Bananen vortrefflich gedeihen (zu reifen Früchten bringen es freilich die letzteren hier so wenig, als anderwärts in Japan). Natürlich muss die dem Strome beim Schmelzen des Schnees zufliessende Wassermasse eine ganz colossale sein und sie ist es auch. In der Nähe der Stadt Nagaoka verbreitert sich der Fluss, zahlreiche Inseln bildend, sebr rasch; diese Inseln und das flache ufer werden im Frühjahr ganz unter Wasser gesetzt, das sich im Mai wieder verlauft, nachdem es viel Sand und Schutt aus den Bergen zurückgelassen.

Vier Kilometer unterhalb Nagaoka, bei dem Dorfe Kurodzu werden mehrere dieser Inseln und die vorher überschwemmten Uferstrecken zum Hanf- und Gerstenbau benutzt und diese Stellen sind der Heerd der Krankheit. Ganz dasselbe ist der Fall bei dem 20 Kilometer flussabwärts gelegenen Dorfe Nishino, wo der Strom eine Breite von 600 Metern erreicht. Gerade hier ändert sich stets das Strombett. In den letzten vier Jahren bat sich das Wasser so in's rechte Ufer hineingefressen, dass ausgedebnte Arbeiten nöthig waren, um das bedrohte Land zu schützen. Mit diesem Wühlen auf der einen Seite ist eine Landbildung auf der anderen verbunden, und so kommt es, dass stets neue Inseln und Uferflächen entstehen, die, cultivirt, neue Ausgangspunkte für die Krankheit

1) S. Stieler's Atlas. 
bilden. In dem Gebiete des Nebenflusses des Shinanogawa trifft die Krankheit 18 kleine Dörfer, die sämmtlich dem Ueberschwemmungsgebiete angehören; alles so eben Gesagte gilt auch für sie. Auch im dritten Gebiete, am Oomonogawa, sind, soweit meine Informationen reichen, die Verhältnisse ganz die gleichen.

Im Juni wird auf den betreffenden Strecken Hanf gesäet, und bei der Ernte desselben erkranken die Schnitter. Solche Leute, welche nur einfach hindurchgehen, oder solche, welche Schiffe bergwärts ziehend am Ufersaum entlang in dem Schilfgras waten, erkranken fast niemals. Alles Weitere siehe bei Aetiologie.

Eine grosse Schwierigkeit für genaue Untersuchungen bietet das Verhalten der Bevölkerung jener Gegenden. Die Thorbeit der Kranken und die Verbohrtheit der Gesunden arbeiteten zusammen, um uns ein klares Urtheil zu erscbweren. Anstatt dass wir bei den Bewohnern der inficirten Dörfer Unterstützung für unsere Bemühungen gefunden hätten, stiessen wir überall auf einen dumpfen Widerstand, ja man möchte fast sagen, auf eine Verschwörung. Obwohl von den Behörden, die uns überall auf's Lobenswertheste unterstützten, ein grosser luftiger Raum zur Verfügung gestellt war, wo die Kranken unentgeldliche Behandlung fanden, so meldete sich doch bei Hern Kawakami 14 Tage lang kein einziger Kranker zur Aufnahme. Ich fand daher bei meiner Ankunft in Kurodzu die Patienten in ihren Häusern oder vielmehr Hütten liegend in einem Schmutze, der jeder Beschreibung spottet. Von Myriaden yon Flöhen und Moskitos zerstochen, in alte elende stinkende Lumpen gehüllt, quälten sich die Unglücklichen in den halbdunkeln rauchigen Räımen. Alle Aufforderungen, sich doch wenigstens zu waschen, blieben unbeachtet; man fand sie am nächsten Tage wie zuvor, starrend vor Unrath. Alle europäischen Arzneien wurden verschmäht; sie seien zu stark, könnten tödten, und überdies schmecken sie ja gar nicht einmal schlecht!! Wenn diesem letzteren sogenannten Uebelstande durch Chinin oder Semina Strychni abgeholfen wurde, so fand sich irgend ein anderer Grund, die Annahme der Arznei zu verweigern.

Ein fernerer Hauptgrund gegen den Eintritt in's Hospital Iag, wie sich bald herausstellte, in dem freilich nicht ganz unbegründeten Verdachte, dass wir die Absicht hätten, in den lethal endigenden Fällen womöglich die Section vorzunehmen. 
Auf diese Weise war nichts zu erreichen, namentlich konnte von genauer Beobachtung und Untersuchung keine Rede sein. Drejmal hatten holländische, in dem nahen offenen Hafen Niigata angestellte Aerzte versucht, die Krankheit zu stadiren, hatten aber, durch die unerwarteten Schwierigkeiten abgeschreckt, jedesmal die Sache als hoffnungslos wieder aufgegeben. Um nicht dasselbe thun zu müssen, blieb uns kein anderes Mittel, als die Unterstützung der Polizei anzurufen. Auf diesem Wege gelang es endlich, die Patienten in's Krankenhaus zu bringen, und die dort gemachten Beobachtungen sind es vor Allem, die der Fieberbeschreibung u. s. w. zu Grunde gelegt sind.

\section{Begriffsbestimmung.}

Das japanische Fluss- oder Ueberschwemmungsfieber ist eine aljührlich in den Monaten Juli und August an gewissen, im Frühjahr überschwemmten Stellen auftretende, acute, nicht contagiöse Infectionskrankheit von typischem, fieberhaftem Verlauf, mit umschriebener Hautnekrose beginnend und zu Lymphdrüsenschwellung und Hautexanthem führend.

$$
\begin{gathered}
\text { Symptomatologie. } \\
\text { Allgemeines Krankbeitsbild. }
\end{gathered}
$$

Die Symptome des Flussfiebers sind im Allgemeinen so übereinstimmend und so charakteristisch, dass selbst die leichtesten abortiven Fälle ohne Weiteres als hieher gehörig erkannt werden.

Wir beschreiben zuerst die ganz ausgebildeten, häufigsten Formen und schliessen daran die Beschreibung der unausgebildeten und der complicirten Fälle.

Die Latenzzeit beträgt, wo sie sich überhaupt deutlich nachweisen lässt, 4-7 Tage. Ihre Dauer ist aber häufig auch nicht einmal annähernd festzustellen, weil sich die Leute täglich der Infection aussetzen. Die Latenz bezieht sich auf die subjectiven Erscheinungen, denn es ist möglich, dass ein objectives Symptom, die später zu besprechende Hautnekrose, öfters schon in dieser Periode yorhanden ist, aber wègen seiner Unbedeutendbeit und Unscheinbarkeit der Aufmerksamkeit entgeht.

Eigentliche Prodrome fehlen fast stets; wo sie vorkommen, bestehen sie in unbestimmten Störungen des Allgemeinbefindens, in 
schlechter Stimmung, Eingenommenheit des Kopfes, Unlust zur Arbeit, schlechtem Appetit, urid zwar dauern diese Symptome zwei bis drei Tage, wodurch dann die Latenzzeit um ebenso viel verkürzt wird.

Der eigentliche Ausbruch der Krankheit erfolgt meist am 6. Tage nach dem Aufenthalt auf dem gefährlichen Alluvium oder nach Bescbäftigung mit der von dort gebrachten Frucht, mit einem ziemlich heftigen Frösteln, das sich, abwechselnd mit Hitze, im Laufe des ersten Tages wiederholt, mit Kopfschmerz, Gefühl von Klopfen in den Schläfen, Appetitlosigkeit und einem starken Schwächegefühl, das die Kranken zwingt sich niederzulegen. Diese Symptome müssen in der That sehr intensiv sein, da sich sonst dieses harte, an schwerste körperliche Arbeit gewöhnte Volk gerade zur Erntezeit sicherlich nicht niederwerfen liesse. Die Kranken haben meist von vorn herein Verdacht auf Tsutsuga mushi und suchen selbst nach dea charakteristischen Symptomen, die sie spätestens am zweiten Tage nach dem Beginne des Fiebers zu finden pflegen.

Das erste dieser Symptome ist in der Regel eine Schmerzhaftigkeit der Lymphdrüsen in einem Bezirke des Körpers, an einer Leiste, einer Achselhöhle, am Halse u. s. f. Die Schmerzhaftigkeit wird meist durch directe Prüfung, seltener bei irgend einer Bewegung oder durch Zufall entdeckt, weil sie anfangs ziemlich mässig ist und nur bei Druck eintritt. Sofort wird dann in der Peripherie des betreffenden Theils weiter gesucht, und mit Sicherheit eine mehr oder weniger schwarze trockene schorfartige Stelle gefunden. Diese umschriebene Hautnekrose, beziehentlich das daraus hervorgegangene Geschwür ist das specifische, absolut charakteristiscbe Zeichen des Flussfiebers, das in keinem einzigen Falle fehlt. Jetzt kennen die Kranken ihr Leiden und wenden sich an den Arzt, der dann in diesem Stadium Folgendes findet:

Die Kranken kommen meist zu Fuss mit Unterstützung in's Hospital (es handelt sich stets nur um ganz kleine Strecken Weges), sind aber so schwach, dass sie sich kaum auf den Beinen halten können und wie Betrunkene taumeln. Wenn man sie in ihren Wohrungen aufsucht, liegen sie in sich zusammengezogen da, als ob sie sich vor Kälte schützen wollten. Das Gesicht, im Stehen etwas blass, ist im Liegen intensiy geröthet. Die Kranken wimmern 
fast unaufhörlich, geben aber ausser dem nicht einmal besonders heftigen Kopfschmerz und allgemeinem Unbehagen keinen Grund für diese Laute an, die sie während der ganzen Dauer der Krankheit ausstossen. Sie sind im böchsten Grade empfindlich gegen den geringsten Luftzug, und haben eine tiefe, fast unüberwindliche Abneigung gegen Berührung ihrer Haut mit kaltem Wasser, ja mit Wasser überhaupt ${ }^{1}$ ). Manche Kranke erwähnen geradezu als erstes subjectives Krankbeitszeichen eine abnorme Empfindlichkeit gegen Luftzug oder Wind (letzteres leichte Winde bei einer Schattentemperatur von $25-30^{\circ} \mathrm{C}$.). Die Blutwärme schwankt zwischen $38^{\circ}, 5$ und $39^{\circ}, 5$, der Puls ist relativ wenig trequent, beträgt bei

1) Es ist eine auffallende Thatsache, dass die Japaner, die unstreitig doch mehr als irgend ein anderes Volk der Welt auf Baden halten, und die ich oft habe sagen hören, dass ein anständiger Mensch sich unwohl und unrein fühle, wenn ar arel Tage kein Bad genommen hat, in Krankheiten eine unglaubliche, nur durch den fast religiösen Einfluss lang ererbter Vorurtheile erklärbare Scheu vor Wasser haben. Während im Allgemeinen ein schmutziger Körper selbst bei den niederen Ständen wenigstens der Städte eine Seltenheit ist, starren Kranke bei ihrer Aufnahme in das Krankenhaus of förmlich von Schmutz, und es ist mir in Tokio vorgekommen, dass Patienten lieber das Hospital sofort wieder verliessen, als sich dem reinigenden Einlluss des Wassers aussetzten. Selbst Wärterinaen konnten nur durch Strenge dazu bewogen werden, Kranke zu waschen.

Was ich so eben über die Vorliebe der Japaner für das Baden gesagt habe, bezieht sich nur auf das warme oder eigentlich heigse Wasser von $45-50^{\circ}$ C.; in Tokio finden viele Leute Wasser von $42^{\circ} \mathrm{zu}$ lau oder kalt, um darin zu baden. Natürlich müssen so heisse Bäder die Körpertemperatur wesentlich beeinflussen, und zwar ist die Erhöhung in sämmtlichen Fällen ebenso bedeutend als rapid. Ich beobachtete bei einem 21 jährigen kräftigen Mann im Bade von $49^{\circ} \mathrm{C}$. in $6 \frac{1}{2}$ Minuten ein Ansteigen der Temperatur (unter der Zunge gemessen) von $36^{\circ}, 6$ auf $40^{\circ}, 6$. Dass eine Erhöhung um $4^{0}$ binnen wenigen Minuten nicht blos dem Organismus nicht schädlich ist, sondern geradezlı ein Gefühl des Behagens bervorrufen kann, ist meines Wissens bisher noch nicht constatirt worden. Indessen ist diese Steigerung die höchste, die îch in so kurzer Zeit sah; $2-3^{0}$ aber kamen bäufig vor. Die Pulsfrequenz steigt ebenfalls colossal, zuweilen um 60 Schläge und mehr.

Alles Nähere werde ich später in einer Studie über das heisse Bad ausführlich besprechen.

Bis zur Ankunft der Fremden war auch das Trinken kalten Wassers in den meisten Theilen des Landes streng verpönt; jetzt ist diese Abneigung in's Gegentheil umgesehlagen und das Eiswassertrinken im Sommer hat, wie in Amerika, fast bedenkliche Dimensionen angenommen. 
Månnern ca. 80, bei Frauen bis 100 und darüber. Die Haut ist trocken, ohne Exanthem. An irgend einer Stelle des Körpers, meist wo die Haut weich ist, am häufigsten an Scrotum, Achselhöhle, Hypochondrium, oder auch an irgend anderen Stellen findet man eine 2-4 Mm. im Durchmesser haltende, runde, schwärzliche oder blauschwarze Stelle, die in der Mitte manchmal eine leichte Vertiefung zeigt. Sie ist stets scharf gegen die kaum infiltrirte, weiche, lividrothe Umgebung abgegrenzt. Das Schwarze ist ein Schorf, eine vertrocknete, nekrotische Gewebspartie. Der Schorf ist trocken, äusserst hart und zäh, sehr schwer ablösbar. Der ganze Prozess ist eigentlich eine rein locale Mumification. Natürlich ist die Stelle gegen Nadelstiche unempfindlich, aber die Entfernung in diesem Stadium, weil in der Tiefe die nekrotische Partie noch nicht abgegrenzt und noch wie mit Fäden in das gesunde Gewebe eingefilzt ist, meist ziemlich schmerzhaft; in manchen Fällen standen wir, um die Kranken nicht unnöthig aufzuregen, zunächst ganz von der Ablösung $a b$, so sehr sie im Interesse der Reinlichkeit wünschenswerth erscheinen mochte. Die nächste Umgebung ist kaum erhaben, und was bei der acuten Natur des ganzen Prozesses gewiss auffallend ist, spontan und bei Druck gar nicht schmerzhaft. Einige Tage später, wenn sich die Demarcation in der Tiefe vollendet hat, lässt sich die Kruste leichter entfernen und man findet nur ein rundes Kratergeschwür mit ganz scharfen steilen Rändern, wie nach Ablösung einer Rypiaborke bei Syphilitischen. Der scheinbar speckige Grund mit einem tieferen Löchelchen in der Mitte stellt sich aber nicht als eiterbelegt heraus, sondern besteht aus einer ziemlich consistenten zähen Masse, von der man mit der Pincette nur einzelue ganz kleine Fetzen ablösen kann. Dies kommt daher, dass die Zahl der Eiterkörperchen bei der geringen Reaction relativ sehr klein ist, dass vielmehr eine langsame köraige Einschmelzung des Gewebes mit völliger Erhaltung aller elastischen Fasern stattfindel.

Ein durch Gesicht oder Gefühl erkennbarer lymphangitischer Strang liess sich in unseren Fällen niemals nachweisen, dagegen war starker Druck auf die Stellen zwischen der Schorfstelle und den zugehörigen Lymphdrüsen öfters schmerzhaft. Die letzteren sind ausnahmslos vergrössert und gegen Druck äusserst empfindlich, so. dass die Patienten dabei zusammenzucken und schreien. Meist 
erreicht eine Drüse nahezu die Grösse einer Wallnuss, die anderen die Grösse einer Haselnuss oder einer Bohne. Die Consistenz ist halbhart, lange nicht so fest, wie bei den meisten anderen acuten Drủsenschwellungen; dabei bleiben die Drüsen jsolirt und sind stets leicht beweglich. Die Schmerzhaftigkeit und Schwellung beschränkt sich aber nicht auf diese Drüsen, sondern ergreift, wenn auch in geringeren Grade, fast alle oberflächlichen fühlbaren Lymphdrüsen. Die übrigen Erscheinungen sind wenig auffallend. Nabezu constant ist die Conjunctiva betheiligt, und zwar nicht, wie bei den Masern, in Gestalt gewöhnlicher katarrhalischer Conjunctivitis, sondern die Conjunctiva palpebrarum ist weniger afficirt als die Conjunctiva bulbi. Diese zeigt eine discrete Injection der tiefer liegenden episcleralen Gefässe, und hat daher einen blaurothen Anstrich. Sonderbarer Weise ist diese Injection der Conjunctiva ziemlich regelmässig aussen stärker als innen. Der ganze Bulbus erscheint wie geschwollen, vorgetricben, glotzend, und erinnert an den Bulbus Erstickter. - Nase und Rachen sind fast stets normal.

Husten mit gleichzeitig nachweisbaren katarrhalischen Rasselgeräuschen auf der Lunge ist bäufig. Der erste Herzton ist öfters unrein. Die Zunge ist feucht, wenig belegt, ziltert nicht. Milz stets, aber nur mässig, vergrössert, Dämpfung durchschnittlich $8: 12 \mathrm{Cm}$. - Urin klar, gelb, hochgestellt, ohne Eiweiss. Meist ziemlich hartnäckige Verstopfung.

Dieser Befund des dritten oder vierten Tages verändert sich zunächst wenig, nur das Fieber nimmt zu; es erreicht am Abend des 5. oder 6. Tages Abends stets $40^{\circ}$ und darüber und nimmt den Charakter einer Continua, seltener einer Remittens an. Die Pulsfrequenz ist noch jmmer relativ niedrig.

Am 6. oder 7. Tage bricht unter weiterer Steigerung des Fiebers, der Unruhe, der Angst ein Exanthem aus. Gewöhnlich zeigt es sich zuerst im Gesicht an den Schläfen und Wangen in Gestalt grosser, flacher, unregelmässiger Papeln oder auch Quaddeln von dunkelrolher Farbe, ähnlich der der Masernflecke. Oft einen halben Tag später, oft gleichzeitig erscheint es an den Vorderarmen und Unterschenkeln, am Rumpfe; an Oberschenkeln und Oberarmen ist es undeutlich; der Hals und Gaumen bleiben gewöhnlich verschont, nur ausnahmsweise werden am letzteren punktförmige rothe Flecke beobachtet. Gleichzeitig mit den Papeln und zwischen 
denselben stehen an den Vorderarmen und am Rumpfe äusserst zahlreiche Lichenknötchen. Das Exanthem bricht allmäblich hervor, juckt nicht, und sein Ausbruch führt keine subjective Erleichterung herbei. . Es danert unregelmässig lange, durchschnittlich 4-7 Tage und ist bald deutlicher, bald undewtlicher. In leichteren Fällen ist es zuweilen nur einen Tag sichtbar. Die Dauer des Exanthems bezeichnet das Höhestadium der Krankheit. Das Fieber ist continuirlich, der Puls voll, nie dicrot, macht 80-100 Schläge p. M. Die Patienten sehen erhitzt aus, deliriren bei Nacht öfters, geben aber auf Befragen stets klare Antwort, jammern viel. Schwerhörigkeit ist bäufig, die Conjunctivae sind noch stärker geröthet, die Augen glänzen. Die Lippen sind trocken, rissig, bluten leicht. Die Zunge ist in wirklich schweren Fällen ganz trocken, glatt, schwer beweglich. Zahnfleisch dunkel geröthet, häufig schmerzhaft und zu Blutung geneigt. An Stelle des Schorfs findet man jetzt meist ein Geschwür, das mässig stark Eiter absondert. Husten jst in geringem Grade fast immer vorhanden, in einzelnen Fällen ist er heftig, anfallsweise, rauh, heiser und bildet das quälendste Symptom für die Kranken, die er nicht schlafen lässt. Die Respiration, namentlich bei Frauen und Kindern, ist sebr beschleunigt; Rasseln auf der Lunge ist häufig, Dämpfung u. s. w. haben wir nie gefunden. Das Epigastrium ist ebenso, wie das rechte Hypochondrium, gegen Druck zuweilen etwas empfindlich, was dann stets schwere Fälle anzeigt. Die Milz ist nach wie vor mässig, selten stark, noch seltener fast gar nicht vergrössert. Stuhlgang meist nur durch Klystiere oder Abführmittel zu erzielen. Der Urin ist hell, gelb, spec. Gewicht 1025-1030, Menge vermindert; kein Sediment, kein Eiweiss.

Am Ende der zweiten Woche, in leichten Fällen etwas früher, in schweren etwas später, macht das Fieber grosse Remissionen, und es tritt dann, schneller als bei Typhoid, aber langsamer als bei Masern, eine Besserung im Befinden der Kranken ein. Man findet sie eines Morgens mit normaler oder nahezu normaler Temperatur, und sie erklären ganz unaufgefordert, dass es ihnen besser gebt, sie fühlen sich leicht im Kopfe und haben nicht mehr das schwere Krankheitsgefühl. Dem entspricht auch ibr ganzes Wesen. Der Blick ist freier, das Gesicht, vorher stark geröthet, ist blass geworden; es regt sich ețwas Appetit; aber am Nachmiltag kommt wieder eine Fiebersteigerung und das wiederholt sich drei oder vier 
Tage mit allmählich niedrigeren Abendtemperaturen, bis das Fieber ganz verschwunden ist. In dieser Zeit lebhafter Appetit, bäufig lejchte Diarrhoe, dabei der Stuhl normal gefärbt. Der Urin wird reichlicher, wässeriger, hat öfters einen Bodensatz von harnsauren Salzen.

Die Reconvalescenz ist rasch, die Kranken sind noch blass, lassen sich aber, nachdem sie zwei bis drei Tage ohne Fieber sind, nicht mehr im Krankenhause halten.

An diese so zu sagen normalen Fälle schliessen sich die leichteren Formen unmittelbar an und sind mit ihnen durch Uebergänge verbunden. Die Symptome der Haut, d. b. der Schorf und die Drüsenschwellung, sind constant auch hier vorhanden, aber die Allgemeinerscheinungen sind geringer. Manche Kranke legen sich nur für ein paar Tage zu Bett, haben sehr mässiges Fieber, geringes oder gar kein Exanthem; wieder Andere, die eigentlichen Abortivfälle, zeigen ausser geringen Störungen des Allgemeinbefindens (und selbst diese können fehlen), etwas Müdigkeit, Verdauungsstörung und Kopfschmerz, gar keine Symptome. Nach unseren diesjährigen Erfahrungen betragen diese Fälle über 25 pCt. der Gesammtzahl; in anderen Jahren sollen sie seltener sein. Aus den Localaffectionen lässt sich die geringe Reaction nicht erklären; das grösste Geschwür, das ich sah, $2 \mathrm{Cm}$. im Durchmesser, hatte ein ambulanter Kranker. Die Drüsenschwellung dagegen ist geringer und namentlich sind die entfernteren Drüsen gar nicht oder fast gar nicht geschwollen. Offenbar handelt es sich hier um Modificationen der Intensität des Giftes oder um Verschiedenheiten in der Disposition zur Erkrankung.

Den leichten Fällen gegenüber stehen die schwersten complicirten Formen, die oft zum Tode führen. Seltener ist es das Fieber an sich, welches durch seine Höhe Gefahr bringt, meist handelt es sich um hinzutretende andere Verbältnisse, acute rapid wachsende Parotitis, reichliche, blutige, theerartige Stähle, oder um Nervensymptome, und zwar bald Coma, bald Manie oder Herzschwäche, Lungenödem etc. Bei Schwangeren ist Abortus häufig, meist mit tödtlichem Ausgange.

\section{Analyse der einzelnen Symptome.}

1. Temperatur.

Die Temperatur hat bei dieser Krankheit einen typischen Verlauf, welcher sie den typhösen Krankheiten anreiht. Der Typus 
wird aber in den leichten Fällen mebr verwischt und ist weniger ausgeprägt, auch ist die Dauer des Fiebers weniger constant, als es bei jener Krankheitsgruppe der Fall zu sein pflegt. Der Beginn ist plötzlich, aber nie durch einen Schüttelfrost gekennzeicbnet; dagegen fehlt Frösteln und eine grosse Empfindlichkeit gegen Kälte uud Zugluft niemals. Dem entsprechend steigt die Blutwärme nicht, wie bei Pneumonie oder Wechselfieber, jäh an, sondern man findet in den ersten Tagen Morgentemperaturen von $38 \frac{1}{2}^{\circ}$ und Abendtemperaturen von $39-39 \frac{1}{2}^{\circ}$. Die einzige Messung, die bei einer Kranken am ersten Tage gemacht wurde (ohne zu wissen, dass Flussfieher vorlag), ergab $38^{\circ}, 5$.

Die gewöhnlich bei typischen Fiebern unterschiedenen drei Stadien des Anstiegs, der Höhe und des Abfalls lassen sich auch hier deutlich erkennen und baben in voll ausgebildeten Fällen eine ziemlich bestimmte Dauer. Das erste Stadium, das Ansteigen, dauert bis zum 5. oder 7. Tage, und geschieht, sofern die wenig zahlreichen hierher gebörigen Beobachtungen allgemeine Schlüsse zulassen, in der Weise, dass an jedem folgenden Morgen die Remissionen geringer und am Abende die Werthe der Steigernng höher ausfallen; also ähnlich dem Verhalten, das wir beim Abdominaltyphus kennen. Am Ende der ersten Woche ist $40^{\circ}, 40^{\circ}, 5$ oder selbst (aber sehr selten) $41^{\circ}$ erreicht, und wir stehen damit im Stadium der Höhe. Während desselben, etwa vom 7 . bis 12. oder 14. Tage, ist das Fieber entweder eine Continua mit Remissionen von etwa 0,6 oder eine Remittens mit Differenzen von ca. $1^{\circ} \mathrm{zwischen}$ Morgen und Abend. Der Abfall geschieht am Ende der zweiten oder im Anfange der 3. Woche in Gestalt einer Lysis im Laufe von 5 bis 6 Tagen. Zuerst pflegen sich, bei gleichbleibender Höhe der Abendwärme tiefere Morgenabfälle einzustellen, die also als prognostisch günstiges Zeichen angesehen werden müssen; erst etwas später fallen auch die Abendhöhen geringer aus, um schliesslich ganz auszubleiben.

Das war wenigstens der Verlauf in den von uns in einem frühen Stadium übernommenen Fällen. In vernachlässigten Fällen hingegen zieht sich das Fieber mehr in die Länge, bis in die 3., selbst 5. Woche. Leicbtere Fälle haben entweder geringere Maximaltemperaturen oder sie machen tiefere Remissionen. Auch die Dauer des Fiebers ist geringer, ja in ambulanten Fällen ist dasselbe äberhaupt böchst unbedeutend. 
Die Aehnlichkeit einer Fiebercurve von Flussfieber mit einer von Typhus lässt sich nicht verkennen. Z. B. stellt die Curve III, wenn man von den beiden durch Salicylsăure bedingten tiefen Remissionen absiebt, einen zusammengedrängten Typhus, oder noch mehr, eine gewöhnliche Form einer Typhusrecidivcurve dar. Auch die Curven I und II beweisen diese Aehnlichkeit ${ }^{1}$ ). Dem gegenüber stehen aber dann andere, namentlich leichte Fälle, bei welchen davon nichts zu bemerken ist, und die, weil sie keinen Werth haben, hier nicht reproducirt sind.

Die subjective Besserung am Ende der ersten Woche ist durch die erste tiefe Fieberremission bezeichnet.

Eine Eigenthümlichkeit beim Flussfieber ist wohl noch die ganz frappante Regelmässigkeit, mit welcher die Maximaltemperatur in die Zeit um 6 Uhr Abends fällt, während um 8 Uhr oder $10 \mathrm{Uhr}$ die Wärme stets wieder um einige $\frac{1}{10}$ bis $\frac{1}{2}$ Grad oder selbst um einen Grad gesunken ist.

2) Puls.

Die Pulsfrequenz ist während des Fiebers gesteigert, aber in so geringem Grade, dass man zur Erklärung fast annehmen muss, dass sich dabei die Hemmungsnerven des Herzens im Zustande der Erregung befinden, ähnlich wie beim Abdominaltyphus. Die gewöhnliche Pulsfrequenz für erwachsene männliche Flussfieberkranke beträgt 90 , während man nach Liebermeister's Berechnung 105 als Parallelzahl erwarten sollte. Wie bei Frauen uberhaupt und namentlich im Typhus die Pulswerthe etwas höher und variabler ausfallen, als bei Männern, und hohe Zahlen bei ihnen nicht die gefürchtete Bedeutung haben, wie bei Männern, so haben wir auch beim Flussfieber bei Frauen grössere Pulsfrequenz gefunden, meist 100 und darüber. Andererseits aber finde ich doch bei einer 27jährigen Frau eine Temperatur von 39,3 und gleichzeitige Pulsfrequenz von 84 yerzeichnet. Bei Kindern und Jünglingen ist natürlich die Pulsfrequenz gleichfalls höher, gewöhnlich 100 oder mehr. Dass der Puls sich im Aufsitzen auffallend beschleunigt hätte, konnte nicht gefunden werden. Dicrotismus kam nicht vor. Die Pulswelle ist gross, hart. In den ersten Tagen der Reconvalescenz kann die Pulsfrequenz etwas unter die Norm fallen: so

1) Die Curven sind leider nicht angekommen. Solten sie nacbgeliefert werden, so sollen sie nachträglich veröffentlicht werden.

D. Redact. 
hatte ein 11 jähriger Knabe in dieser Zeit nur 64 Schläge p. M. Doch scheint dieses Verhalten eine Ausnahme zu sein.

Ominös ist es, wenn bei normaler oder fast normaler Temperatur der Puls frequent wird. Diese Erscheinung haben wir nur bei den schwersten Fällen beobachtet, bei denen in der 3. oder 4. Woche ernste Gehirnsymptome auftraten, die gewöhnlich zum lethalen Ausgange führten. Glücklicherweise indessen sind diese Fälle nicht zahlreich, sie betragen noch nicht 10 pCt. der Gesammtzahl (vergl. hieza die Krankengeschichten No. 6 und 7).

3) Ha $\mathrm{H} \mathrm{t.}$

Da sich ein grosser Theil der Erscheinungen auf der Haut abspielt, so ist ein genaueres Eingehen auf dieses Organ nothwendig. Was zunächst die primäre Hautnekrose ${ }^{1}$ ) betrifft, so ist sie in der grossen Majorität der Fälle in der Einzahl vorhanden, so in sämontlichen 25 von mir beobachteten Fällen; doch wird angegeben, dass auch zwei, drei und selbst vier Schorfe zu gleicher Zeit vorkommen können, und sollen dann die Fälle besonders schwer verlaufen. Der Sitz des Schorfes ist meist an weichen, warmen und etwas feuchten Hautstellen, und zwar fand ich ihn am Scrotum 7 , Achselhöhle 6, Hypochondrium 2, Hals 2, Ohr, Wirbelsäule, Infraclavicnlargegend, Mamillargegend, Leiste, Oberschenkel je 1 Mal. Diese Schorfe sind stets schon deutlich vorhanden, wenn die Kranken danach suchen, und es ist nicht unwahrseheinlich, dass ihre erste Eutwicklung in eine frühere Zeit, das sogen. Latenzstadium fällt, so dass dieses objectiv vielleicht kaum existirt. Aber da die Stellen jedenfalls anfangs sehr klein sind und bei ihrer völligen Schmerzlosigkeit von den Kranken auf ihrer, durch Floh- und Moskitobisse gereizten und stets mehr oder weniger zerkratzten, schmutzigen dunkeln Haut nur sehr schwer wahrgenommen werden können, selbst wenn sie vorbanden sind, so kann dies nur Vermuthung bleiben. Bis etwas Genaueres darüber bekannt wird, müssen die ersten Tage Latenzstadium genannt werden - und sie sind es ja auch in Wirklichkeit, wenn man Latenz die Zeit nennt, in der nichts bemerkt wird, und nicht, in der nichts bemerkt werden ka n $\mathrm{n}$.

Wein die Kranken den Hautschorf bemerkt haben, so wenden

1) Ich spreche von primärer Hautnekrose und nicht von Pastel, Abscess, weil ich niemals die letzteren Erkrankungsformen beobachtet habe. Dass vielleicht ganz im Anfang doch ein Blăschen oder Pustelchen vorbanden ist, ist immerhin möglich. 
sie sich an den (chinesisch erzogenen) Arzt, und dieser legt obne zu reinigen ein schwarzes Pflaster auf, das alle drei oder vier Tage gewechselt wird und an dem das eine oder andere Mal der Schorf hängen bleibt. So entwickelt sich unter fortwährender Berührung mit Schmutz und Schmiere ein Geschwür, das manchmal etwas grösser wird, als dem ursprünglichen Schorfe entspricht. Eine Reinigung der Geschwüre, ein Waschen derselben und ein Verbinden mit einer indifferenten Salbe gilt fast als Verbrechen. Kümmert man sich aber um solche Vorurtheile nicht und behandelt man die gereinigte kranke Stelle ganz indifferent, überlässt sie also so zu sagen sich selbst, so bemerkt man, dass der Schorf allmählich locker wird und in der zweiten Woche ohne alle Mühe entfernt werden kann. Er lässt dann das besprochene runde, wie mit dem Locheisen herausgeschlagene Geschwür zurück, das, anfangs fast gar nicht secernirend, allmäblich unter reichlicherer Eiterbildung durch Granulation von der Tiefe aus heilt. Die Zeitdauer der Heilung ist versebieden; es kamen uns Geschwüre vor, die in 8 Tagen, andere, die erst nach fünf Wochen heilten; aber geheilt sind sie alle obne jeglichen Schmerz, ohne Neigung zur Ausbreitung, ohne Entzündung in der Umgebung. Beim Volke besteht der Glaube, dass ein frühes Zuheilen ungünstig sei, weil das Gift den Körper nicht verlassen könne, und es sieht daher eine reichliche Eiterung gerne. Das ist aber lediglich ein Vorurtheil, für das man ja seine Analoga im ärztlichen und nichtärztliehen Publicum anderer Länder findet. In Kurodzu gab es leichte Fälle, bei welchen das Geschwür sebr schnell heilte, und ganz schwere Fälle, bei denen es nach vier Wochen noch offen war. Dennoch gestehe ich, dass ich das Geschwür selbst künstlich offen erhalten hätte, wenn es nur gelungen wäre, in dem Schorfe oder in dem Eiter oder im Gewebe des Geschwürsgrundes oder endlich im Blute irgend etwas zu entdecken, was als dem Körper schädlich hätte angesehen werden können, z. B. grosse Massen von Bakterien. Gerade das frühzeitige Auftreten des Schorfes und die folgende Lymphadenitis machen es wabrscbeinlich, dass darin die Eintrittsstelle und nicht erst die Folge des Krankbeitsgiftes vorliegt, und wenn auch für Krankheitsstoffe durchaus nicht, wie für Teufel und Gespenster, das Gesetz gilt, dass sie, wo sie herein sind, wieder heraus müssen, - früher erblickte man in den Krankheiten ja Dämonen, - so bleibt doch die Möglichkeit 
des Nutzens einer eiternden Fläche nicht ausgeschlossen. Das war es auch, was uns zu immer erneuten Untersuchungen veranlasste ohne Erfolg. In keinem einzigen Falle fanden sich in Schorf, Eiter, Gewebsfetzen Bakterien, auch nur in der Menge, wie man sie sonst, selbst in notorisch aseptischen Wunden, häufig genng antrifft. Der Schorf war immer beschaffen, wie jeder andere Schorf auch. Das gelbe nekrotische Gewebe gleicht unter dem Mikroskope einem aus einer Wunde herausgezogenen Fetzen Sehnengewebe oder einem Stückchen Furunkelpfropf. Die schwarze Kruste besteht aus Epidermis, dem reichlich mit rothem und mit in die schwarze Modification übergegangenem Blutfarbstoff durchsetzten Papillarkörper, der eigentlichen Cutis, und endlich aus viel Schmutz, was bei der mangelhaften Reinlichkeit der Leute und bei ihrer Beschäftigung nicht Wunder nehmen kann. Sitzt die Nekrose an behaarten Stellen, so findet man natürlich auch die Haare sammt den Haarbälgen in der Kruste festsitzend. Ob aber der Haarbalg den Ausgangspunkt bildet, lässt sich in diesen Fällen schon nicht mehr nachweisen. Zuweilen bildet sich nach Abnahme des ersten Schorfs eine neue Kruste. Von etwaigen Milben, Insecteneiern u. dgl. war nirgends eine Spur zu entdecken.

Das secundäre Exanthem. Die Haut dieses Landvolkes, das den gaozen Tag nackt (nur mit bedeckten Genitalien) in der glühenden Sonne arbeitet, hat eine tiefbraune, eigentlich rothbraune Farbe, und die Frauen, die, nur von der Taille bis zu den Knien bekleidet, gleichfalls Feldarbeit verrichten, sind kaum lichter gefärbt. Dazu kommt, dass tagtäglich zabllose Flöhe und Moskitos darauf Nahrung suchen und finden, so dass der Körper oft ganz mit rothen Flecken, Punkten und Quaddeln bedeckt ist. Das macht die Diagnose und namentlich die Detaillirung eines leichten pathologischen Exanthems ungemein schwierig, ja in manchen Fällen unmöglich. Da ausserdem die Kranken nur mit dem äussersten Widerstreben dulden, dass ibre Haut gewaschen wird, so sieht sich der Arzt oft in einer difficilen Lage. Es ist uns in mehreren Fällen so ergangen, dass wir nicht wussten, ob wir Quaddeln und Papeln auf die Krankheit oder auf Insectenstiche beziehen sollten. Immerhin aber sind das Ausnahmen und in der Regel ist das Exanthem irgendwo am Körper so klar und deutlich, dass man es nicht übersehen oder verkennen kann. Es zeigt sich am Ende der ersten Woche zur Zeit der grössten Fjeberhöhe. Fast immer bemerkt 
man es zuerst im Gesicht, an Wangen und Schläfen; doch erscheint es zuweiler auch zuerst an den Armen und am Rumpfe. Am letzteren und am Halse ist es am wenigsten ausgeprägt. Es tritt in zweierlei Form auf, erstens in Gestalt grosser Papeln von der Farbe des Scharlachexanthems ${ }^{1}$ ), die im Gesicht auf den Wangen gerne confluiren, auf dem Rumpfe aber stets discret stehen, manchmal deutlich nach den Spaltrichtungen der Haut geordnet, und zweitens in der Form kleiner, ebenso gefärbter Knötchen. Diese letzteren pflegen auf den Vorderarmen am reichlichsten und deutlichsten zu sein. Sie scheinen von den Haarbälgen auszugehen, denn es gelingt bäufig, ein Härchen in der Mitte zu entdecken. Eine diffuse, confluirende, über den ganzen Körper verbreitete Röthe soll vorkommen, wenigstens gaben zwei Reconvalescenten an, anfangs wie von einern Lackexanthem ${ }^{2}$ ) befallen gewesen $\mathrm{zu}$ sein, worunter meist ein Erythem, seltener Quaddeln verstanden werden. Das Exanthem dauert fast eine Woche, selten länger, und hat die Eigenthümlichkeit, dass es vorübergehend bald schwächer, bald deutlicher sichtbar wird, auch wohl für einen Tag verschwindet, um am nächsten Morgen wiederzukehren. In den schwereren von uns beobachteten Fällen blieb der lichenőse Ausschlag bis tief in die 3. Woche der Krankkeit hinein bestehen, nachdem das papulöse Exanthem schon völlig verschwunden war. Petechien sind selten, doch spricht das nicht ganz seltene Zurückbleiben gelbbrauner Flecke während der Recon-

1) Ich sage absichtlich: von der Farbe des Scharlachexanthems, und nicht: scharlachfarben, denn ich kano durchaus nicht finden, dass der scarlatinöse Ausschlag die wirkliche Scharlachfarbe besitzt.

2) Die Berührung der Haut mit dem flüssigen japanischen Lack (von Khus vernicifera) ruft bei einzelnen dazu disponirten Individuen ein ätsserst intensives dunkelrothes Erythem hervor, das furchtbar juckt. und schmerzhaft ist. In anderen Fällen entsteht allgemeine Urticaria, oder ein verbreiteter Lichen, oder auch ein miliariaähnlicher Bläschenausschlag. Wer besonders stark mit dieser Idiosyncrasie behaftet ist, der braucht nur ein Zimmer zu betreten, in dem sich flüssiger oder halbtrockaer Lack befindet, oder an einer Lackwaarenfabrik vorbeizugehen, um sofort zu erkranken. Einer meiner Bekannten bekam beim Einschliessen mikroskopischer Präparate, — wozu sich der Lack vortrefflich eignet - ein äusserst starkes, multiformes Exanthem - das Gesicbt sah aus wie bei Erysipel -, mit Fieber bis $40^{\circ}$. Die Prognose ist stets günstig. Trockner Lack ist ungefährlicb. Da der reizende Stoff eine flüchtige Säure sein soll, so ist das altgebrăuchliche Volksmittel, gepulverte Krebsschalen in Wasser suspendirt einzureiben, ganz rationell. 
valescenz dafür, dass etwas Blutfarbstoff die Gefässe verlassen haben muss. - Das Exanthem juckt nicht und wird von dem Kranken meist gar nicht bemerkt. - Es kann in leichten Erkrankungsfällen ganz fehlen. In zwei sehr schweren Fällen sahen wir ein lichenähnliches oder auch an einzelnen Stellen kleinfleckiges Exanthem auf dem harten und namentlich auf dem weichen Gaumen. Die Kranken standen in der 2. Woche. - Die Schweissabsonderung auf der Höhe der Krankheit ist stark; bei einzelnen Kranken entwickeln sich reichliche Sudamina.

4. Lynuhsystem.

Die regelmässige Betheiligung der dem Hautschorf benachbarten Lymphdrüsen durch schmerzhafte Anscbwellung gehört zu den Cardinalsymptomen der Krankheit und ist, wie schon erwähnt, gewöhnlich dasjenige Zeichen, wodurch die Patienten zuerst auf die Natur ihres Leidens aufmerksam wurden. Dass die Affection der Lymphdrüsen ursprünglich vom Schorfe aus fortgepflanzt ist, kann kaum zweifelhaft sein, obwobl man nicht, wie man docb eigentlich erwarten sollte, die die Fortpflanzung vermittelnden Lymphgefässe entzündet findet. Wahrscheinlich ist eine grössere Menge von Krankheitsgift nöthig, um Entzündung zu bewirken, und dienen die Lymphdrüsen bier, wie sicher in so manchen anderen Krankheiten, als eine Art Filter, ja als Schutz für den übrigen Körper; sie halten eine gewisse Menge von Krankheitsstoffen zurück, schwellen dadurch an und entzünden sich. Genügt aber das Filter nicht, gebt doch noch ein Theil weiter im Lymphsystem, so wird der ganze Körper krank. Das ist hier offenbar der Fall. Alle Lymphdrüsen sind geschwollen, aber die am weitesten von der Stelle des Krankheitsheerdes entfernten am wenigsten. Noch am meisten geschwollen sind die symmetrisch gelegenen Drüsen, also z. B. bei Geschwüren rechts am Scrotum neben den rechten Leistendrüsen die linken, bei Sitz in der rechten Achselhöhle neben den rechten die linken u. s. w. Dass die Drüsen nicht sehr hart und dass sie leicht beweglich sind, hat wohl seinen Grund darin, dass die Entzündung sich auf das Drüsengewebe selbst beschränkt, während das umgebende Gewebe ganz frei bleibt. Bej einer Kranken mit Nekrose im rechten Hypochondrium war von dieser Stelle aus in directer Richtung nach der Achselhöble Druck etwa $10 \mathrm{Cm}$. weit schmerzbaft, dann kam eine ganz scbmerzlose Stelle, bis $8 \mathrm{~cm}$. vor der 
Achselhöhle wieder Schmerz bei Druck begann. Die Drüsen waren stark geschwollen, sehr schmerzhaft.

Die Schmerzhaftigkeit der übrigen Drüsen ist stets nur mässig, sie verliert sich in der Regel bald, und noch ehe das Fieber geschwunden ist, sind diese Drüsen zur Norm zurückgekehrt; während bei den dem Schorf benachbarten die Empfindlichkeit bis tief in die Reconvalescenz hinein fortbesteht. Die Schwellung der Drüsen ist rein parenchymatös, es besteht durchaus keine Neigung zur Vereiterung; ja selbst eine voriabergehende Röthung der darüberliegenden Haut kam nicht vor.

5. Blutgefässsystem.

Dieses ist, abgesehen von Exanthem und Lymphdrüsen, wenig alterirt. Niemals hat sich ausser einem vorübergehend beigemischten ersten Geräusch beim ersten Tone an der Herzspitze oder einem leichten systolischen Blasen an der Aorta irgend etwas Abnormes am Gerzen nachweisen lassen. Der Herzstoss war wohl bei hohem Fieber etwas verbreitet und stark, aber die Dämpfung war stets normal. Nur in den schlimmsten, lethal endigenden Fällen ist das Herz beim schlechten Ausgang wesentlich betheiligt, indem es insufficient wird. Die Frequenz der Herzschläge nimmt zu, der Puls wird weicher, kleiner, es treten die Zeichen von Lungenödern auf u. s. w. Die Carotiden und Schläfenarterien klopfen auf der Höhe der Krankheit stark, was den Kranken recht lästig ist. Ueber den Puls siehe oben.

6. Respirationsapparat.

Die Nase ist stets frei. Geringes Nasenbluten wird nicht ganz selten zur Zeit des Exanthems beobachtet und hat dann etwas Erlejchterung zur Folge. Der Kehlkopf meist normal; nur in 2 Fällen ( 8 pCt.) wurde mässige Heiserkeit beobachtet. Der in reichlich $50 \mathrm{pCt}$. aller Fälle vorkommende Husten ist zum Theil auf eine Affection des Keblkopfs, zum Theil auf eine solche der Langen zurückzuführen; ersteres in den seltenen Fällen von Heiserkeit mit lange dauerndem, anfallsweisem, raubem, fast bellendem Husten, während auf der Lunge überall reines Vesiculäratbmen zu hören ist, letzteres in der Majorität, wenn bei normaler Stimme gar kein Kitzel oder Schmerz im Kehlkopf vorhanden ist, dagegen an den Lungen (namentlich hinten unten) starkes Rasseln oder Pleifen und Schnurren besteht. Bei einem 11 jänrigen Knaben bildete der Husten 
während des ganzen Krankheitsverlaufs das auffallendste Symptom; es standen die einzelnen Hustenanfälle denen eines heftigen Keuchhustens an Intensität wenig nach. Die Respirationsfrequenz betrug hier 48 pro Minute. Gewöbnlich war sie weit gepinger, etwa 30-36 pro Minute, und zwar selbst in denjenigen Fällen, wo gar keine Bronchitis bestand, und das Fieber sehr mässig war. $O b$ aber deshalb eine directe Einwirkung des Krankheitsgiftes auf das Athemcentrum angenommen werden muss, ist höchst zweifelhaft; ich glaube vielmehr, dass das beständige Wimmern hier, wie überall, wo es auftritt, eine Beschleunigung der Respiration herbeifuhrt. Eine anfallsweise auftretende, offenbar zum Theil nervöse Dyspnoe kam bei einer 23jäbrigen Kranken zur Beobachtung, sie verlor sich mit den übrigen Krankheitssymptomen. Bronchitis, wo sie vorkommt, ist meist diffus, und erstreckt sich nur auf die grösseren Bronchien; der Auswurf dabei ist spärlich, zäh schleimig, später schleimig-eitrig. Pneumonie, katarrhalische oder croupöse, kam nie vor.

Lungenödem bildete bei den tödtlichen Fällen hier, wie anderwärts, das Terminalsymptom.

7. Verdauungapparat.

Hier sind die Störungen sehr mannichfach. In allen mittelschweren und schweren Fällen sind die Lippen trocken, springen leicht auf und bluten. Das Zahnfleisch ist von der zweiten Woche an etwas geschwollen, und gegen Ende des Fiebers entwickelt sich nicht selten ein leicht scorbutischer Zustand, so dass die Patienten beständig Schmerzen im Munde haben und nicht gut kauen können. Manche klagen zugleich über Zahnschmerz, oder über das Gefühl, als ob ihnen die Zähne zu lang wären. Der Appetit ist bei dem hohen Fieber natürlich gering, doch sind die Kranken so unvernünftig, beständig Kürbisse, Mrlonen, Apfelsinen, unreife Pfirsiche und alles mögliche Unverdauliche zu essen oder essen zu wollen.

Die Zunge ist in ganz schweren Fällen stets, ebenso wie die Lippen, trocken, an den Rändern fuligiıös, schwer beweglıch, und beim Herausstrecken etwas zitternd. Dabei ist sie aber meist in der Mitte ganz glatt, wie polirt, helfflessebroth. In allen anderen Fällen siebt die Zunge relativ gut aus, sie ist, trotz hoben Fiebers, entweder gar nicht oder doch nur wenig belegt, etwas weisslich angeflogen. Ein dicker Zungenbelag ist mir nie vorgekommen. 
Gaumen und Rachen sind frei, mit Ausnabme des oben erwähnten, in zwei Fällen beobachteten Exanthems. Tonsillen und Uvula normal, keine Schlingbeschwerden. Parotitis acuta hatte ein Kranker; sie war rasch entstanden, bald darauf erfolgte der Tod in äusserster Entkräftung.

Erbrechen als Anfang der Krankbeit tritt nicht ein, ebenso ist es im Verlauf der Krankheit sebr selten, und erfolgt stets nur dann, wenn die Patienten Diätfehler gemacht haben. Druckempfindlichkeit im. Epigastrium gilt als böses Zeichen; es war bei zwei Kranken vorhanden, die beide starben. Ziemlich hartnäckige Verstopfung ist die Regel, so dass Klystiere und Abführmittel nöthig sind, nach deren Wirkung in der Regel subjective Erleichterung eintritt. Mehrmals wurde auch durch ărztlicherseits berbeigeführte starke Ausleerungen ein bedeutender Fieberabfall erzielt. Die Farbe des Stuhles ist, wie bei den reisessenden Japanern überhaupt, gelb. Gegen Ende der Krankheit macht öfters die Verstopfung einer leichten Diarrhoe Platz. Blutiger Stuhl kam bei zwei Kranken vor, von denen einer starb; aber auch bei diesem kann der blutige Stuhl nicht als Todesursache betrachtet werden, vielmehr war der Patient auch sonst in einem hoffunngslosen Zustande. Der Stubl zeigte zahllose seidenglänzende Punkte, Cholestearinkrystalle. In diesen beiden und in einem dritten Falle, von dem mir der Arzt in Nishino erzäblte, waren die Stühle theerartig, dickbreiig, und traten 4-5 mal täglich ein, stets unwillkürlich. Die Zeit ist das Ende der zweiten oder der Anfang der dritten Woche, wenn das Fieber schon nachlässt, doch hörte ich von einem Kranken, der auf der Höhe der Krankheit bei $41^{\circ}$ blutigen Stuhl halte und nachher, wenn auch sehr langsam, genas.

Leber: Sie ist nur ganz ausnahmsweise etwas vergrössert; wir beobachteten dies bei einem der Kranken, die blutigen Stubl hatten. Icterus fehlt. Die Milz ist rom ersten Anfang des Fiebers an vergrössert, doch ist die Vergrösserung sebr unbedeutend. Wir fanden fast stets die Dämpfung 8:12 Cm. oder 10:12 Cm. und das unverändert durch die ganze Dauer der Krankheit. Nur einmal betrug die Dämpfung $12: 15 \mathrm{Cm}$. und bei einem Schwerkranken wurde die Milz als harter derber Körper am Rippenbogen gefühlt.

8. Harnapparat.

Die Urinmenge ist auf der Höhe der Krankheit vermindert, aber 
nicht sebr bedeutend, weil die Kranken bestăndig grosse Mengen von Wasser in Gestalt von Limonade, Wassermelonen u. s. w. zu sich nehmen. Die Reaction ist sauer, die Farbe klar, gelb, mit geringem Bodensatz. Specifisches Gewicht 1020-1030. Eiweiss wurde nur in Eiıem Falle gefunden, bei einer schwächlichen, tertiär syphilitischen Frau von 26 Jahren. Die Unglüekliche war von ihrer rohen Familie noch zu schwerer Arbeit gezwungen worden, nachdem sie sich schon eine Woche lang krank fühlte; sie brach auf der Schwelle des Krankenhauses zusammen. $O b$ bei ihr die Albuminurie mit der Syphilis zusammenhing (es waren niemals Oedeme vorhanden, keine sonstigen Zeichen von Speckdegeneration) oder ob sie durch Vernachlässigung der acuten Krankheit entstanden, liess sich nicht entscheiden. Der Urin enthielt sehr spärliche hyaline Cylinder. Die Chloride des Urins waren auf der Höhe der Krankbeit mässig vermindert. Harnstoffbestimmungen konnten wegen Mangels an Apparaten nicht gemacht werden. Nach Abfall des Fiebers erscheint öfters vorübergehend starker Bodensatz von Uraten. Harndrang wiru ziemlich häufig beobachtet.

9. Nervensystem.

Wenn man einen Kranken in der zweiten Woche sieht, so wird man sofort an Typhus erinnert. Das rothe Gesicht, die glänzenden Augen, die trockenen Lippen, die Schwerhörigkeit, die Apathie Alles ist ähnlich; und dennoch ist die. Betheiligung des Nervensystems in beiden Fällen gänzlich versehieden. Beim Flussfieber ist die Apathie und das schwere Verständniss nur scheinbar, in der Regel dadurch bedingt, dass die Patienten schwer hören. Ruft man sie laut an, so dass sie die Worte verstehen, so geben sie stets ganz klare und zutreffende Antwort, und zwar ohne sich erst lange besinnen zu müssen, wie dies die Typhösen thun. Auch ist die Sprache mit ganz seltenen Ausnahmen nicht lallend, sondern wohl articulirt, und dass auch das selbstthätige Denkvermögen nicht schwer leidet, geht aus den Fragen der Kranken hervor. So erkundigte sich ein scheinbar bewusstlos daliegender Kranker kurz vor dem Tode, ob er deun auch wirklich wieder ganz gesund werde, und wie lange Zeit bis dahin vergehen könnte. Delirien sind ziemlich selten.

Viele Erscheinungen deuten im Gegentheil darauf hin, dass eine leichte Reizung in der sensiblen Sphäre während der ganzen Krank- 
heitsdauer vorhanden ist, ähnlich der bei Cerebrospinalmeningitis. Der Kopfschmerz, am ersten Tage auftretend, verliert sich erst mit der ersten tieferen Fieberremission; er ist dumpf, drückend und wird stets in Schläfen und Stirn localisirt. Er bildet stets eine Hauptklage, und dennoch bekommt der Untersuchende nicht den Eindruck, als ob er besonders heftig sein könnte, denn wenn es gelingt, die Kranken in ein Gespräch $z u$ verwickeln, so werden sie ganz munter und scheinen alle ihre Leiden zu vergessen. Gleichzeitig mit dem Fieber beginnt und verschwindet auch das Wimmern und Stöhnen, das in der That höchst auffallend ist, und das, wenn es auch zum Theil mit dem Kopfschmerz zusammenhängen mag, durch denselben nicht völlig erkJärt wird; es muss ein Symptom allgemeiner Hyperästhesie sein, wie sie sich durch die starke Reaction auf geringe äussere Reize und Insulte fast bei allen unseren Kranken kundgiebt. Während im Allgemeinen die Japaner durch ihre Toleranz gegen Schmerz bei Operationen u. dgl. jeden Europäer in Verwunderung setzen, so dass z. B. das Chloroform eine viel kleinere Rolle spielt als bei uns, während sie sich, ohne zu zucken, ruhig ihr Pfeifchen rauchend, mit dem Glüheisen lange Streifen ziehen oder ein halbes Dutzend Moxen hintereinander auf der Haut abbrennen lassen, geberdeten sich die Kranken beim Flussfieber, sobald es sich um Entziehung eines Tropfens Blut durch einen kleinen Nadelstich handelte, wie Kinder, weinten und wehrten sich, ja mehrmals gab es eine solche Scene, dass ich mich schliesslich genöthigt sah, diese Untersuchungen aufzugeben, weil ich sonst sicher alle Kranken verscheucht hätte.

Ausser der Haut ist in schweren Fällen auch die Musculatur hyperästhetisch, so dass Druck auf die Muskeln der Arme und Beine schmerzhaft empfunden wird. Meist verliert sich diese Empfindlichkeit sehr bald.

Zeitlich und in der Art des Auftretens ganz verschieden von dem Bisherigen ist eine Gruppe von Nervenzufällen, die öfters fatal werden. Sie zeigen sich in der 3 . oder 4 . Woche, nachdem schon Besserung oder gar Heilung eingetreten zu sein scheint. Wir haben dreierlei Formen beobachtet, erstens maniakalische Delirien, die sich unter dem Gebrauch von Chloral und Morphium verloren, zweitens Coma mit Ausgang in Tod, und drittens einen überaus heftigen Kopfschmerz mit ängstlicher Stimmung (vgl. die Beobachfung No.9). 


\section{Sinnesorgane.}

Das auffälligste bieher gehörige Symptom ist die schon öfter erwähnte Schwerhörigkeit. Dieselbe muss wesentlich nervöser und nicht entzündlicher Natur sein, da Schmerz im Ohre niemals besteht und von einer Affection des Rachens und der Nase nichts nachzuweisen ist. Daher sieht man auch niemals Perforation des Trommelfells, Eiterung aus dem Gehörgang u. dgl. Die Schwerhörigkeit beginnt erst auf der Höhe der Krankheit und erreicht ziemlich hohe Grade; sie dauert lange und erstreckt sich in die Reconvalescenz hinein, verliert sich aber stets vollkommen, obne irgend welche bleibende Störung zu hinterlassen.

Ferner wäre hier noch zu erwähnen die früher beschriebene Conjunclivitis, und dass die Augen Morgens meisl verklebt sind.

$$
\text { Verlauf, Dauer und Ausgänge. }
$$

Die durchschnittliche Dauer der Krankheit mag für mittelschwere Fälle auf drei Wochen angenommen werden, wovon fast die ganze Zeit auf die fieberhafte Periode und nur wenige Tage auf die Reconvalescenz fallen. Nur ganz ausnahmsweise zieht sich der Prozess so in die Länge, dass das Fieber einen Monat dauert und sich dann erst eine allmähliche Reconvalescenz anschliesst. Durch das Auftreten der erwähnten späteren Nervenzufâlle wird zuweilen ganz unerwartet eine noch fortdauernde Wirkung der erloschen gewähnten Krankheit offeribar. Andererseits daueru leichte Fälle mit geringem Fieber ötters nur eine Woche.

Der Aufenthalt im Hospital ist relativ kurz, indem die Leute ausnabmslos, nachdem sie ein paar Tage ohne Fieber waren, sich durchaus nicht mehr festhalten liessen. Die Erholung geschieht sehr rasch, so dass die Arbeit fast sofort wieder aufgenommen werden kann. Der andere Ausgang, der in Tod, trat bei keinem einzigen der von uns bebandelten Fälle ein, dagegen starben 3 Kranke, die ich nur je einmal gesehen habe, und die sich rundweg weigerten, in's Hospital zu kommen. Das macht eine Mortalität von $12 \mathrm{p} \mathrm{Ct}$. für die beobachteten Fälle. Die gewöhnliche wird zu $15 \mathrm{pCt}$. angegeben.

Die Morbilität, die Zahl der Erkrankungsfälle im Verhältniss zur Bevölkerung, ist in den befallenen Districlen sehr gross; in Karodzu erkrarken jetzt jedes Jabr von etwa 500 Einwohnern 25 bis 
40; früher war die Zahl noch bedeutender, aber jetzt scheuen sich die Leute, auf die gefährlichen Stellen za gehen, selbst wenn der Ertrag daselbst ein guter zu werden verspricht. Die Gesammtzahl aller Fälle im Shinanogawa- und Uedagawathal beträgt jährlich 200, nur im Thale des Oomonogawa, soweit ich es eruiren kann, jedenfalls über 100. Diese Zahlen sind, absolut genommen, freilich klein, sie sind es aber nicht, wenn man bedenkt, wie beschränkt die Verbreitung des Leidens ist, und wie stark es die dortige Bevölkerung decimirt.

\section{Krankbeitsgeschichten.}

No. I. Flussfieber. Mittelschwerer Fall. Genesung. (Curve I.)

N. Takahashi, 21jäbriger Bauer. Zeit der Infection unbekannt. Erkrankte den 1. August 1878 mit Uebelkeit, Kopfschmerz, Müdigkeit. Beim Suchen fand sich eine rothe Stelle rechts am Scrotum, die sich bald in ein flaches Geschwörchen verwandelte. Gleichzeitig starke Drüsenscbwellung in der rechten Leistengegend.

Status praesens am 5. August Morgens. Kräftiger Mapn, liegt apathisch da, ist aber ganz bel Bewusstsein und klar. Gehör normal. Temp. 39,5. Puls 90, voll. Auf der Scrotalbaut recbts ein kleines Geschwür mit steilen Rändern. Lymphdrïsen in der Leiste stark geschwollen und schmerzhaft, die übrigen Drüsen wenig afficirt. Das Geschwür ist spontan etwas schmerzhaft, es ist sebr unrein gehalten. Auf dem Gesicht und den Vorderarmen spärliches flachpapulöses Exantbem. Bei Druek alle Muskeln schmerzhaft. Herz und Lunge normal. Augen injicirt, Lippen trocken, Zunge feucht, glatt, etwas belegt, zittert ein wenig. Milz 8:12. Lebergegend und Epigastrium nicht schmerzhaft. Abends Temp. 39,7.

6. August Morgens: Exanthem vermehrt. Häufiger Urindrang. Abends: Der Kranke wimmert viel, schwitzt sehr stark. Exanthem im Gesicht stärker. Conjunctivae injicirt. Geschwür and Drüsen unverändert. Temp. 32,2. Puls 90. Keine Bronchitis, Muskelschmerz geringer, nur noch an Armen und Beinen deutlich. Milz $8: 12$, Häufiger Harndrang, Menge des Urins gering. Kein Stuhl.

7. August Mittags. T. 40,1, P. 84, Resp. 30. Viel Stöhnen, Wimmern, Nasenflügelathmen. Exanthem viel stärker als gestern, grosspapulös, besonders stark auf Stirn, Wangen und Vorderarmen. Es juckt nicht, die Flecke verschwinden auf Druck, kommen aber rasch wieder, sind von Schinkenfarbe. Das Geschwür ist wellenförmig, flach, granulirt gut. Conjunctiva etwas entzündet, Augen verklebt. Zunge weiss belegt, feucht. Subsultus tendinum. Drüsen überall schmerzbaft. Gesammteindruck der eines Typhösen in der zweiten Woche.

8. August. Gesicht blasser, Gescbwür noch immer schmerzhaft, wabrscheinlich von Erosionen der Umgebung durch Pflaster und Schmutz herrührend. Exanthem an den Vorderarmen noch deutlich. T. 39,9, P. 100.

9. August. T. 40,2, P. 100. Aufnahme in's Krankenhaus. Zuerst gründllehe Reinigung, dann Verband des Geschwürs mit Carbolwasser. Der Schmerz hört sofort auf, aber wegen des hohen Fiebers noch viel Unruhe, Angst, Kopfschmerz. 
Exanthem an den Vorderarmen noch als deutlich erbabene, aber fast farblose Flecke zu bemerken. Muskelschmerz und Drüsenschmerz gering. Blutuntersuchungsresultat negativ. Abends starker Kopfschmerz. Ord.: Karlsbader Salz, Natron salicyl. 2,50).

10. Aug. Der Fall sieht immer schwerer aus. Das Fieber steigt nach dem Abfall durch salicylsaures Natron sofort wieder. Der Patient fängt an, mit Lippen und Händen zu zittern. Wegen Verstopfung Karlsbader Salz. Danach dreimal dünner Stubl. Zunge fast gar nicht belegt, roth, zur Trockenheit neigend. Muskelschmerz, Drüsenschmerz. Urinmenge vermindert. Milz 10:12.

11. Aug. Noch immer intensives Fieber $\left(40^{\circ}, 5\right)$. Fängt an schwerbörig zu werden. Zunge etwas fuliginös. Sprache stotternd. Puls voll, kräftig, nicht dicrot. Mehrmals dünner Stuhl. Exanthem verschwunden. Geschwür granulirt gut.

14. Aug. Hat seit Darreichung des Karlsbader Salzes starke Diarrhoe bekommen, täglich circa 8 Entleerungen; jeder einzelnen geht Kolik und Kollern im Baucbe voraus. Die Menge des Entleerten ist gering, die Consistenz dünn, die Farbe gelblich; kein Tenesmus. Kein Urindrang mebr. Das Aussehen des Kranken blasser, die Augenlider noch verklebt, die Conjunctivae roth, besonders aussen. Etwas Schwerhörigkeit, aber völlige Klarheit im Kopfe, welche mit dem ïbrigen Status typhosus auffallend contrastirt. Leichter Subsultus tendinum. Znnge trocken. Er selbst sagt er müsse eine Katzenznnge haben. Lippen aufgesprungen, bluten leicht. Gar keine Röthung and Schwellung im Halse. Grosse allgemeine Empfindlichkeit. Carotiden und Schläfenarterien klopfen stark. Thorax: Lungen normal, Respiration wenig beschleunigt, gar kein Husten. Herztöne: der erste etwas unrein, alle Töne ausser dem 2. Aortaton dumpf. Leib nicht aufgetrieben. Leber leicht vergrössert, Bauch auf Druck ganz leicht empfindlich. Kein Exanthem. Geschwür am Scrotum eitert noch ziemlich stark. Drüsen weniger geschwollen, aber noch sebr empfindlich. - Ord.: Tinctr. Opii mit Tannin im Klystier.

15. Aug. Schlummert viel, keine Delirien. Fieber nimmt allmählich ab, sonst Alles im Gleichen; der Kranke klagt noch immer viel, hat gar keinen Appetit. Diarhoe etwas geringer.

1) Die Dosis von 2,5 mag in Europa für erwachsene kräftige Männer fast lächerlich gering erscheinen, aber erstens zeigt sich bier eine deutliche, wenn auch mässige Wirkung auf das Fieber, und zweitens habe ich, durch Schaden klug gemacht, meine guten Gründe, mich an kleine Gaben Salicylsäure zu halten. Wober es kommt, dass in Bezug auf Arzneimittel die Japaner so wenig tolerant sind, weiss ich nicht, aber Thatsache ist, dass ich bei Typhus auf Dosen von 3,0 oder 4,0 Natron salicylicum ganz schwere Collapse habe eintreten seben, ja dass einmal eine 30jährige Typhöse durch 2,0 (2 Gramm) Natr. salycil. unter Temperaturabfall ron $5^{0}$ derartig collabirte, dass es die grösste Mübe kostete, dem sofortigen Eintritt des Todes vorzubeugen. Die gewöhnliche wirksame antifebrile Dose, welche Fieberabfälle von $2-4^{0}$ bei Typhus herbeiführt, ist 2,5 Gramm, wofür u. A. Krankengeschichte III. eine gute Illustration bildet. Auch bei dem übrigens bier recht seltenen acuten Gelenkrtseumatismus sind nur kleine Dosen erforderlich. Eine äbnliche geringere Tolèranz oder grössere Wirksamkeit beobachtet man bei Chinin und Calomel.

Das Klima kann daran nicht Schuld tragen, denn ich selbst habe zur Probe 8,0 Natron salicylicum auf einmal genommen, ohne irgend etwas anderes als leichtes Ohrensausen zu verspüren, und ich habe wiederholt Europäer obne allen Schaden 12,0 pro die nehmen lassen. 
17. Aug. In den beiden letzten Tagen aufallende subjective und objective Besserung. Heute Morgen ist Pat blass, die Conjunctivae sinu nicht mehr injicirt; er stöhot nicht; kein Muskelschmerz. Drüsenschwellung fast verschwunden. Geschwür nabezu geheilt. Zunge normal, Appetit stellt sich ein; Gefühl, als ob die Zähne zu Jang wären. Gestern 5mal Diarrboe, beute Vormittag $1 \mathrm{mal}$.

18. Aug. Fortschreitende Besserung. Urinmenge 1200, Gew. 1020, kein Eiweiss; Bodensatz von Uraten.

19. Aug. Hat unverdaulicbes Zeug gegessen, daher etwas mehr Fjeber, sonst Alles gut. Sebr blasses Aussehen.

22. Aug. Hat sich rasch erholt. Drüsen nur noch an der rechten Leiste leicht schmerzhaft. Geschwür ganz geheilt. Miladämpfung 8:12.

23. Aug. Abgang bei erträglichen Kräften. Abmagerung wäbrend der Krankheit relativ gering.

\section{No. II. Mittelschwerer Fall. Genesung. (Curve II.)}

Sorimachi, 34jäbriger Bauer. Zeit der Infection unbekannt, weil er sich jeden Tag der Infection aussetzte. Am 14. August erkrankte er mit Kältegefübl und damit, dass er den Wind nicht ertragen konnte. Daranf heftiger Kopfschmerz, Müdigkeit, geringer Appetit. Legt sich zu Bett. Schickt deu 16. zum Arzte, der hinten an der rechten Schulter eine schwarze Stelle und Schwellung der rechten Axillardrüsen findet. Patient wusste selbst gar nichts davon. - Aufnahme in's Hospital am 17. August, demselben Tag, an welchem sein Sobn geheilt entlassen wurde.

Status praesens den 17. August. Mittelgrosser, leidlich kräftiger Mano mit geröthetem Gesicht, ist ganz munter, bat jetzt wenig Kopfschmerz, klagt nur über Müdigkeit, Schwere in den Gliedera, Hitze, Mangel an Appetit. Temp. 39,7. P. 84, voll, kräftig. An der Haut der rechten Schulter hinten auf gerötheter Grundlage eine 2-3 Mm. im Durchmesser haltende schwarze, in der Mitte etwas vertiefte Stelle, aus einem nekrotischen Schorfe bestehend, der fest anhaftet. Die Stelle ist bei Druck gar nicht schmerzhaft: Axillardrüsen rechts geschwollen, bei Berührung schmerzhaft. Inguinal- und Halsdrüsen wenig geschwollen, nicht schmerzbaft. Keln Muskelschmerz. Schläfenarterien klopfen stark. Conjunctivae injicirt, besonders aussen. Nase frei. Lippen trocken. Zahnfleisch dunkelroth. Zunge feucht, stark gelblich belegt. Keine Schwerhörigkeit. Kein Husten. Herz normal. Bauch etwas aufgetrieben. Milz 9:12. Verstopfung. Urinmenge etwas vermindert.

18. Aug. Hat gut gescblafen, wenig Beschwerden ausser Fiehergefühl und Mattigkeit. Rechte Achselböhle sehr schmerzhaft. Urin trüb, gelblich, ohne Eiweiss, Chloride etwas vermindert.

20. Ang. Das Fieber wird alimählich intensiver, der Kranke etwas schwächer. Dabei Sensorium völlig kiar. Beginnende Schwerbörigkeit. Gesicht ond Conjunctiva stark gerōthet, seit heute früh an den Hypochondrien, den Extremitäten und im Gesicht grosspapulöses dunkelrothes Exanthem, das nicht juckt. Schorf wie früher, trocken, scbwer abziebbar. Alsbald bildet sich eine neue ganz ähnliche Kruste. Drüsen der recbten Achselhöhle nussgross, balbhart, weniger empfindlich als früher. Andere Drüsen noch geschwollen, aber schmerzfrei. Kein Muskelschmerz, aber allgemeine Hyperästhesie, so dass der Kranke laut schreit, als ihm 
ein Tropfen Blut zum Zwecke mikroskopischer Untersuchung aus dem Finger entzogen wird. Die Untersuchung des Schorfes, des Eitars, des Blates mit starken Vergrösserungen (Zeiss, Immersion 2) ist völtig resultatlos. Mund: Zahnfleisch stark geröthet, Zunge feucht, etwas weiss belegt, auf dem weichen Gaumen scharlachfarbiges, kleinpunktförmiges, zum Theil confluirtes Exanthem. Uvula gar nicht geschwollen. Keine Scblingbeschwerden. Seif gestern etwas rauher Husten ohne Auswurf. An den Lungen nichts Abnormes. Milz wie früher. Verstopfung. Urin wie früher.

22. Aug. Gestern nachträglich kleiner Fieberabfall durch salicyisaures Natron. Schlaf gut. Heute Morgen Temp. 39,4. P. 84. Hat keine Schmerzen. Exanthem sehr mässig, theils ans grossen Papeln, thells aus kleinen Knötchen bestehend, letzteres besonders an den Armen. Conjunctiva sehr stark injicirt; an Gaumen noch Spuren des Exanthems. Lippen aufgesprungen, bluten leicht. Zahnfleisch livid. Zunge feucht, zitternd. Unter dem Schorf ein Lochgeschwür mit sehr spärlicbem, leicht vertrocknendem Eiter. Umgebung etwas infiltrirt, gerötbet, gegen Druck and spontan schmerzlos. Achseldrüsen weniger geschwollen. Geringer Husten. Kein Appetit. Nach einem Klystier Stuhlgang. Der Puls ist stets auffallend wenig frequent. - Abends Temp. 40,2, P. 80.

23. Aug. Schläft unruhig, delirirt aber nicht. Gesicht gedunsen, geröthet, Conjunctiva bulbi violettroth injicirt, Thränenfluss. Starke Schwerhörigkeit. Exanthem sebr undeutlich. Geschwür etwas grösser, Acbseldrüsen sebr empfindlich; Muskelschmerz bei Druck. Zunge klebrig, weiss. Etwas Husten. Herzstoss stark, erster Ton unrein. Puls voll, nicht dicrot. Miz 10:15. Nach Klystier 2mal Stubl.

24. Aug. Geringe Besserung. Exanthem verschwunden. Hyperästhesie, Muskeland Drüsensebwellung vermindert. Temperatur erreicht $40^{\circ}$ nicht mehr.

25. Ang. Allgemeine Besserung. Der Kranke ist rubig, schläft viel. Urinmenge circa 1100 , trin klar, ohne Eiweiss. Chloride noch deutlich vermindert. Spec. Gew. 1020. Höchste Temperatur $39^{\circ}, 4$.

27. Aug. Fühlt sich ganz munter, hat Appetit, ist sehr blass. Schwerhörigkeit noch stark. Der Schorf abgestossen, Geschwür granulirt gut. Drüsen schwellen ab. Milz $9: 11$.

29. Aug. Kein Fieber mehr. Reconvalescenz.

1. Septbr. Patient verlāsst das Hospital; fühlt sich genesen.

No. III. Mittelschwerer Fall. Genesung. (Gurve III.)

Sorimachi, 24jährige Frau. War am 3. oder 4. August bei Hochwasser am Ufer beschäftigt, war danach längere Zeit ganz wohl, bis sich am 11. Frösteln, Hitze, Kopfschmerz und Mattigkeit einstelten. Der Arzt dachte an Wechselfieber. Am 14. bemerkte sie zufällig Schmerz in der linken Achselhöhle und Schwellung der Drüsen daselbst, sie vermuthete Flussfieber, sucbte nach der Wunde und fand sie im rechten Hypocbondrium. Schickte zum Arzt.

Status praesens am 14. Aug. 1878. Wohlgebaute junge Frau, im 5. Monat schwanger, liegt mit geröthetem Gesicht, viel stöhnend (besonders bei Bewegungen) auf dem Rücken. Giebt gut Antwort, spricht lebhaft. Sensorium völlig frei. Temp. 39,6. Puls 102. Resp. 30. Klagt über Hitze, Kopfschmerz, Mattigkeit, Ohrensausen, Zahnschmerz, Husten, häufigen Drang zum Orinlassen. Haut: Etwas Sudamina auf 
Schulter und Bauch. Im rechten Hypochondrium eine $2 \mathrm{Mm}$. im Durchmesser haltende, gegen die leicht infiltrirte, blassrothe Umgebung scharf abgegrenzte, schwarze Stelle, spontan und auf Druck schmerzlos. Diese schwarze Stelle ist eine oberflächliche Nekrose. Der Schorf ist lederartig zäh, wie mumificirt, schwer abnehmbar. Nach seiner Entfernung bemerkt man einen kleinen, tiefen, lochförmigen Substanzverlust, aus dem allmählich etwas seröse Flüssigkeit, kein Eiter, herausquillt. Von der Wonde aus nach der Achselhöhle zu, also nicht dem Intercostalraum folgend, besteht Schmerzhaftigkeit gegen Druck, aber nirgends ist Lymphangitis sichtbar oder fühlbar. Etwas unterhalb der Achselhöble verliert sich die Schmerzhaftigkeit. In der Axllla selbst mehrere, über bohnengrosse, sehr empfindliche Drüsen. Die Drüsen des übrigen Körpers geschwollen, aber nicht schmerzhaft. Geringer Muskelschmerz bei Druck. Conjunctiva beiderseits, besonders aussen, stark injicirt, bläulichroth. Schläfenarterien stark pulsirend. Kein Schnupfen. Lippen trocken, Zunge feucht, belegt, etwas zitternd. Zahnfleisch etwas geschwollen und geröthet. Schmerz im Larynx. Viel trockner quälender Husten. Auf der Brust bioten unten etwas Pfeifen und Schnurren, wenig Rasseln, Herzdâmpfung normal, der erste Herzton unrein, anstatt des ersten Aortenstosses ein blasendes Geräusch. Bauch aufgetrieben, Uterusfundus reicht nach oben beinabe zum Nabel. Druck auf's Epigastrium etwas empfindlich. Leber nicht vergrössert. Milz 9:12. Verstopfung.

Die mikroskopische Untersuchung des Schorfes ergiebt ausser einigen Mikrococcenhaufen gar nichts Auflallendes: Blutfarbstoff in scbwarzer Form, rothe und weisse mehr oder weniger zerfallene Blutkörperchen, Hautgewebe mit überaus reichlichen, oft ganz isolirten, elastischen Fasern bedecken das Gesichtsfeld. Auch das Serum, bei starker Vergrösserung gesehen, zeigt nichts Charakteristisches.

15. Aug. Morgens. Hat wenig geschlafen, aber nicht delirirt. Kopfschmerz, Schwindel, Obrensausen, Zahnschmerz. Zunge trocken, Stimme heiser. Viel Husten, fast gar Kein Auswurf. Sonst Alles im Gleichen. Urinmenge vermindert, Beschaffenheit des Urins, wie gewöhnlich bei Fieherkranken.

16. Aug. Klagt über Unruhe, Angst, Husten. Schläft schlecht. Puls voll, kräftig, nieht dicrot. Zunge trocken. Geringe Schwerhörigkeit, aber völlig freies Sensorium. Heiserer Husten. Conjunctiven noch stark injicirt. An der Haut des ganzen Körpers zeigen sich einzelne grössere und kleinere Papeln, von denen aber schwer zu sagen ist, wie viele von Flohstichen herrühren. Nach einem Klystier Stublgang. Ordin.: Ipecac. mit Aqua laurocerasi und Morphium.

17. Aug. Hat unrulig geschlafen. Auf dem ganzen Körper reichliches Exanthem; im Gesicht namentlich auf den Wangen, wo es aussieht wie confluirte Masern; auf dem Rumpfe und den Extremitäten steben theils einzelne Papeln oder Quaddeln, die auf dem Bauche mit der Längsrichtung deutlich den Spaltrichtungen der Haut folgen, theils ganz kleine lichenartige Knötchen. Das Exanthem juckt gar nicht. Temp. 39,2. P. 100, voll bart. Auf der Wunde neuer Schorf, wie der alte beschaffen. Drüsen im Gleichen. Zunge feucht, fast gar nicht belegt. An Gaumen und Rachen kein Exanthem. - Abends. Wegen hohen Fiebers $\left(40^{\circ}, 4\right)$ 2,5 Natron salicylicum, danach starker Temperaturabfall (auf 37,8 ); beftiges Obrensausen; das letztere geht bald vorüber.

18. Aug. Wegen Husten wenig Schlaf. Heute früh noch etwas Ohrensausen, 
aber grosse Erleichterung gegen früher, namentlich seit Auflegen einer Eisblase auf den Kopf. Temp. 38,8. P. 108. Zunge feucht, Exanthem undeutlicher, als gestern, ist jetzt rein lichenös. Schorf wie gestern. Lymphdrüsen desgleichen. Nach einem Klysma Stuhl. Jrin geht beim Husten meist unwillkürlich ab (bei ganz klarem Sensorium); seine Farbe ist gelb, klar. Spec. Gew. 1022. Kein Eiweiss. Chloride sind mässig vermindert. Unter dem Mikroskap zeigt der Urin keine abnormen Bestandtheile. Abeads: Temp. 40,4. Viel Unruhe, Angst. Exanthem wieder deutlicher. Natron salicyl. 2,5.

19. Aug. Hat einige Zeit nach dem Einnehmen des Natron salicylicum erbrochen, aber das Mittel hat doch gewirkt. Hat etwas geschlafen. Temp. 38,1. Hente früh Ohrensausen, Kopfschmerz. Husten stark. Auswurf spärlich, etwas blutig; aber nicht wie bei Pneumonie. An der Lunge nur etwas Hasseln. Exanthem wieder sebr stark auf den Wangen confluirt.

20. Aug. Hat gestern Nachmittag viel gestöhnt, gehustet, Nacbts delirirt. Athmung ist frequent (36). Exanthem blasst ab, ist aber noch deutlich sichtbar. Schorf noch festsitzend, schwarz. Drüsen der rechten Achselhöhle noch sehr empfindlich, alle anderen schmerzfrei. Kein Muskelschmerz. Viel Kopfschmerz. Zunge rotb, halbtrocken, Zahnfleisch schmerzhaft, etwas geschwollen. Gaumen und Rachen normal. Stimme etwas heiser, an den Lungen etwas Rasseln, nirgends Dämpfung. Sputa schleimig-eitrig. Statt des 1. Aortatones leichtes Geräusch. Hartnäckige Verstopfung. Milz wie früher. Urinmenge stark vermindert. Urin klar, gelb, ohne Niederschlag, ohne Elweiss oder andere abnorme Bestandtheile.

21. Aug. Nach wiederholten Klystieren sebr reichlicher Stuhl und grosse Erjeichterung. Exanthem wird undeutlich, Conjunctiva fast normal. Zunge nicht mehr belegt, zittert noch etwas. Geschwür beilt. Drüsen scbwellen ab, etwas Appetit. Höcbste Temperatur 39,8.

22. Aug. Heate früh zum ersten Male normale Temperatur. Die Kranke sieht sehr blass aus, ist völlig munter. Hat gar keine Beschwerden mebr. Milzdämpfung noch $8: 12$.

23. Aug. Geschwür geheilt, Achseldrüsen rechts noch etwas geschwollen, lebhafter Appetit. Urinmenge normal. Gar kein Urindrang. Dann und wann noch etwas Husten.

25. Aug. Kann schon etwas gehen. Milz noch $8: 10$.

28. Aug. Fast völlig geheilt entlassen.

Die Fiebercurve dieses Krankheitsfalles zeigt an zwei Stellen, wie kleine Dosen von Salicylsäure nothwendig sind, um bei Japanern starke antipyretische Effecte zu erzielen.

No. IV. Leichter Fall.

24 jäbriger Mann. Er füblte am 28. Juli Kopfschmerz, darauf Fieber und dann erst bildete sich zuerst eine rothe Stelle, die schwarz wurde und endlich zu einem Geschwüre führte. Er war mehrere Tage lang bettlägerig, hatte etwas Drüsenschwellung, kein Exanthem. Heute, am 6. August, ist links am Scrotum ein flaches, etwas speckig aussehendes Geschwür von $3 \mathrm{Mm}$. Durchmesser zu bemerken: Pat. ist offenbar scbon fast ganz hergestellt. 
No.V. Schwerer Fall. Acute Parotitis. Tod.

31jähriger Mann. Erkrankte den 20. Juli mit Fieber, nachdem er sich schon 3 Tage vorher nicht recht wohl gefühlt hatte. Damals hatte er eine wunde Stelle in der linken Achselböhle mit Schwellung und Schmerzhaftigkeit der benachbarten Drüsen. Nach weiteren 4 Tagen Exanthem über den ganzen Körper zu gleicher Zeit; dasselbe dauerte 10 Tage; dann wurde das Fieber noch beftiger und der ganze Zustand schlimmer; mehrmals schwararother blutiger Stubl. Seit 5. August rasch wachsende Schwellung der rechten Backe.

Status praesens. 6. Aug. Grosser kräftig gebauter, aber abgemagerter Mann, sieht schwer krank aus, athmet tief und frequent. Temp. 38,0. P. 86, weich. Das Gesicht ist gedunsen, rechts ist die ganze Parotisgegend geschwollen, fühlt sich sebr derb an, ist spontan and namentlich bei Druck sebmerzhaft. Der Kranke kann den Mund nicht gut öffnen, kann aber ganz gut schlucken. Augen wie geschwollen, Conjunctivae stark injicirt, Pupillen normal. An den Lippen mehrere folliculäre Geschwüre; Zahnfleisch geschwollen, blutet leicht; Zunge fuliginös. Etwas Schwerhörigkeit. In der linken Achselböhle ein speckig belegtes, kleines Geschwürchen, lochartig, mit steilen Rändern. Drüsen jetzt nur sebr wenig geschwollen. Lungen etwas katarrhalisch, Herz normal. Lebergegend bei Druck sehr empfindich, Milz fast gar nicht vergrössert. Stublgang mehrmals täglich, seit 1 Tag grün, vorher schwarz. Fast beständig Delirien. Häufig Zuckungen um die Mundwinkel und an den Händen. Schwere Prostration. - Der Kranke weigerte sich (auf die Reden seiner Verwandten hin), Arznei zu nehmen, oder sich auch nur waschen zu lassen. Er starb, wie man mir berichtete, nach 24 Stunden, nachdem die Geschwulst im Gesicht noch bedeutend gewachsen war. $0 \mathrm{~b}$ etwa ein binzugetretenes, durch Fortpilanzung entstandenes Glottisödem den tödtlichen Ausgang beschleunigt hatte, weiss ich nicht.

Bemerkenswerth in diesem Falle ist der Status typhosus bei fast normaler Temperatur $\left(3^{\circ}\right)$.

No. V. Schwerer Fall. Blutige Stühle. Tod.

31 jähriger Mann. Am 24. Juli erkrankt mit Mattigkeit, seit 28. Juli bettlägerig. Am selben Tage zafälig eine Pustel am Scrotum bemerkt, die obne allen Schmerz entstanden war. Schwerhörigkeit seit 1. Aug., Exanthem seit 4. Aug.

Status praesens 12. Aug. Schwerkrank aussehender Mann mit klarem Bewusstsein, aber sebr schwerhörig. Conjunctivae stark injicirt. Auf der Haut der Vorderarme ziemlich starkes papulöses Exanthem, am übrigen Körper sebr spärlich. Temp. 38,5. P. 114. Zähne schwarz belegt, Zunge ganz roth, glatt, trocken, schwer heweglich; fleckiges Exanthem am weichen Gaumen. Etwas Schluckbeschwerden. Milz 10:15, fühibar. Lebergegend druckempfindlich. Leistendrüsen beiderseits stark geschwollen und schmerzhaft. Andere Drüsen gleichfalls etwas ge8chwollen. Mässiger Muskelschmerz. Etwas Unsicherbeit in den Bewegungen.

13. Ang. Etwas besser, aber seit gestern 4mal theerartiger Stubl. Temp. 38,5. P. 112 .

Am 29. wurde mir mitgetheilt, dass der Kranke gestorben sei.

Die folgenden drei Fälle sind durch die secundären Nervenerscheinungen interessant. 
No. VII. Secundäres Cioma. Tod.

Nishikawa, 63jährige Frau, hatte nach Angabe ihrer Verwandten die Krankheit bereits überstanden und war ziemlich weit in der Reconvalescenz fortgeschritten, als sie allmählich immer müder und schläfriger wurde, und schliesslich in einen comatösen Zustand verfiel. Seit dem 1. Aug. hatte sie gar keine Nahrung zu sich genommen.

Status praesens den 5. Aug. Stark abgemagerte alte Frau, liegt, in sích zusammengekrümmt, völlig bewusstlos $\mathrm{da}$, reagirt auf Anrufen und auf äussere Reize gar nicht; lässt Stubl und Urin nnwillkürlich abgehen. Das ursprüngliche Geschwür geheilt. Keine Drüsenschwellung melr. Temp. 36,5. P. 90, regelmässig, kräftig. Respirationsfrequenz 24. Lippen trocken, Zunge ist nicht zu sehen, weil die hranie die Zähne fest zusammenbeisst. Pupillen sehr eng, reagiren fast gar nicht auf Licht. Keine Contractur, keine Lähmung. Die Verwandten Jassen die Frau ruhig im Schmutze liegen und bekümmern sich gar nicht um sie. - Ord.: Einflössen von Sherry; reizende Klystire.

6. Aug. Temp. Morgens 37,0, Mittags 36,8. Liegt noch immer somnolent da, reagirt aber etwas auf starkes Anschreien durch undeutliches Gemurmel. Keine eigentliche Lähmung. Augen ganz dick verklebt. - Ord.: Eisstückchen zwischen die Lippen. Excitantia.

7. Ang. Ist jetzt im Kopfe viel freier, stöbnt vlej, giebt, wenn auch mit lallender Stimme, Antwort auf an sie gerichtete Fragen. Zunge halbtrocken, wenig belegt, klebrig, wird schwierig herausgestreckt. Stuhlgang und Urin gehen noch unwillkürlich ab. Temp. 37,0. P. 112, etwas schwach.

8. Aug. Sehr schläfrig, hat keine Erinnerung an die letzte Woche. Seit gestern 4mal unwillkürliche dünne Stähle. P. 110. Kein Fieber, isst etwas Reissuppe.

11. Aug. Bewusstsein klar, aber die bisher normale Temperatur fällt auf 35,8 , der Puls von 110 auf 64 . Aeusserste Schwäche.

13. Aug. Nachmittags 5 Ubr ruhig gestorben.

No. VIIL. Maniakalische Delirien In der Reconvalescenz. Hellung.

Eine 21 jährige, mittelschwer erkrankte Frau trat am Anfang der dritten Woche mit Abfall des Fiebers in die Reconvalescenz ein. Einige Tage später brachen ohne alle Vorboten maniakalische Delirien, Wutbanfälle aus, die Kranke schrie, sang, wollte davonlaufen etc. Unter dem Gebrauch von Korphium und Chloralbydrat trat im Lanfe einer Woche vollkommene Herstellung ein.

No. IX. Schwerer Kopfschmerz in der Reconvalescenz.

48 jähriger kräftiger, wohlgenăbrter Mann. Hatte sich nach Ueberstehung der Krankheit ganz wohl befunden und war dann nach weiteren 14 Tagen mit heftigem unaufhörlichem Schmerz über den ganzen Kopf erkrankt, so dass er Tag und Nacht keinen Augeablick Ruhe fand. Er fählte sich völlig unfähig zu jeder geistigen Thätigkeit, meinte, der Kopf wolle ỉhm zerspringen, und fürchtete, verrückt zu werden. Der Kopfschmerz ist bohrend, pressend, sein Kopf ist zu eng u. s. w., dabei ist das Sepsorium völlig klar und die genaueste Untersachung lässt keine Abnormităt entdecken. Ordin.: Morphium und Chloralhydrat. - Ich habe den Mann nur einmal gesehen und nachher nichts mehr öber ihn erfahren können.

Archiv f. pathoi. Anat. Bd. LXXVIII. Hft. 3 , 
Diese Krankenbeobachtungen mögen genügen, um ein hinreichend klares Bild der Krankheit zu geben; sie enthalten alles Wesentliche, was im gewöhnlichen, zjemlich einförmigen Verlaufe an Symptomen beobachtet wird. Es ist möglich, dass zahlreichere neue Beobachtungen diesem Bilde einige neue Züge hinzufügen; dass sie es irgend wesentlich modificiren werden, ist im höchsten Grade unwahrscheinlich.

\section{Pathologische Anatomie.}

Leider steben hier sehr wenige Erfahrungen zu Gebote; ich selbst babe gar keine Section gemacht, dagegen war Herr Kawakami 1877 so glücklich gewesen, zwei Obductionen vornehmen zu können. Er bat darüber Folgendes notirt.

An der Haut der einen Leiche da und dort rothe Flecke, die sich als Petechien auswiesen. An der Nase eine Blutkruste.

Das Blut der Leichen war sehr dunkel, auffallend flüssig.

Die Lungen zeigten übereinstimmend unten starke Staung, ihre Farbe war daselbst blauroth; beim Einschneiden floss viel Blut aus, wenig Luft. Mehrere Stellen waren hart und tleischfarbig (katarrbalische Pneumonie?). Bronschialschleimhant stark geschwollen, geröthet.

Herz. Das Fleisch ist weich, leicht zerdrückbar, die Klappen etwas lebhafter injicirt als gewöhnlich.

Leber gelb (beide Verstorbene waren Potatoren gewesen), sieht ans, wie bel fettiger Degeneration.

Milz vergrössert, in beiden Fällen leichte Perisplenitis.

Nieren. Kapsel leicht abziehbar. Pyramiden etwas vorgetrieben. Corticalsubstanz und Pyramidengrenze undeutlicher als gewöhnlich.

Darm. An der Schleimbant des Dünndarms nahe der Ileo-Cöcalklappe sieht man da und dort rothe, stark injicirte, etwas erbabene Stellen. Dieselben entsprechen nicht immer Peyer'schen Fanfen und sind völlig verschieden von der Erkrankung des Darmes bei Typhus. Der übrige Darm ist anämisch. Die Mesenterialdrüsen sind etwas geschwollen. Das Bauchfell an Magen und Leber ist lebhaft injicirt, ebenso das 0mentum. Entzündung ist nicht vorbanden.

Dieser Bericht ist zwar an und für sich sehr mager, aber er zeigt doch, dass alle Organe wohl beachtet und betrachtel worden sind; er ist hauptsächlich werthvoll dadurch, dass nichts von deutlichen tocalisationen gefunden worden ist. Bedauerlich ist, dass die besonders erkrankten Drüsen nicht mikroskopisch untersueht werden konnten. Herr Kawakami hatte sie herausgeschnitten, sie waren aber bis zur Ankunft in Tokio schlecht geworden. 
Aetiologie und Pathogenese.

Dieser Theil der Untersuchung war der schwierigste, und seine Resultate sind auch wohl jetzt noch als nicht völlig über allen Zweifel erhaben festgestellt. Ich möchte hier noch einmal auf die in der Einleitung erwähnten Hindernisse für eine gründliche Untersuchung, namentlich für eine genaue und verlässliche Anamnese hinweisen. Und gerade auf die Anamnese kam es viel an, hier, wo der eine Hauptfactor, die Ueberschwemmung, ihre Ausdehnung, ihre bestimmte Beziehung zur Krankbeit eruirt werden sollte, wo es sich darum handelte, festzustellen, ob wirklich ein directer Besuch des überschwemmten Landes nothwendig sei, ob dorther gebrachte Gegenstände auch inficiren können, ob nicht vielleicht durch solche Gegenstände die Häuser selbst Infectionsheerde werden können. Auch die Besprechung des Einflusses der Akamushi mag zeigen, wie schwer uns die Erforschung der Thatsachen gemacht wurde. Diese ausserhalb liegenden Hindernisse mögen mich beim Leser und Kritiker entschuldigen, wenn er Lücken findet. Immerbin aber kann ich für das, was ich über Pathogenese sage, mindestens ebenso gute Beweise beibringeu, als für manche mit grosser Zuversichtlichkeit und Sicherheit in Lehr- und anderen Büchern vorgetragene Hypothesen gegeben werden.

Dass die vorliegende Krankheit bisher in der Pathologie unbekannt, dass sie eine scharf umschriebene besondere Krankheit sei, darüber kann nicht wohl ein Zweifel bestehen, und es ist daher auch nicht nöthig, die Einführung einer neuen Species (sit venia verbo) dadurch zu rechtfertigen, dass die Merkmale, die sie von anderen Krankbeiten unterscheiden, einzeln durchgegangen werden. Namentlich bedỉrfen die hier an Ort und Stelle ausgesprochenen Vermutbungen, dass Typhus oder Pest vorliege, keiner Widerlegung. Mit Pest besteht ja uberhaupt keine Aehnlichkeit, und was Abdominaltyphus betrifft, so mögen die beigegebenen Krankheitsgeschichten für sich selbst reden.

Die Hauptschwierigkeit lag in dem Nachweis des Verhältnisses der sog. Akamushi zu unserer Krankheit. Diese Akamushi sind Milben, offenbar mit Leptus autımnalis verwandt, und stellen gleich ihm einen Jugendzustand dar. Sie haben ebenso, wie Leptus, nur 6 Füsse, mit langen Borsten besetzt. Sie sehen roth aus, theils von einem rothbraunen, in ihrer Körperdecke enthaltenen Farbstoff, theils durch das Blut, das sie getrunken haben. Ihre Grösse be- 
trägt durchschnittlich $0,15 \mathrm{Mm}$. So lange sie ruhig auf der Haut sitzen, sind sie wegen ihrer Kleinheit gar nicht bemerkbar, aber doch aus den Symptomen überaus leicht zu diagnosticiren. Sie verursachen nehmlich nach allgemeiner Angabe ein ganz charakteristisches, mit nichts zu verwechselndes, prickelndes Gefuhl, oder auch einen ganz leichten Schmerz, den man übrigens nicht so obne Weiteres genau localisiren kann. Fährt man aber mit der Hand oder mit einem Tuchstückchen über den befallenen Körpertheil, so fühlt man genau an der Stelle, wo die Milbe sitzt, einen Stich und findet beim scharfen Zusehen daselbst einen rothen Punkt. Man sticht dann mit einer Nadelspitze ein und entfernt den rothen Punkt, der manchmal lebendig ist und davon läuft. Nachher wird Tabaksaft eingerieben. Ist die Entfernung gelungen, so bekümmert man sich nicht weiter um die Sache, und nach 2-3 Tagen ist jede Spur von Schmerz u.s. w. verschwunden und die Bissstelle nicht mehr zu sehen.

Nach Angabe des Arztes zu Nishino und desjenigen zu Urasa war der ursächliche Zusammenhang zwischen Flussfieber und Milbe leicht nachzuweisen, indem aus der Stelle, wo sich die letztere eingebohrt hatte, die Hautnekrose, beziehentlich das Geschwür hervorging, das im Anfang der Krankheit beobachtet wird. Andererseits erklärten sämmtliche Leute in Kurodzu die Zurückfuhrung auf Akamusbi einfach für eine Lächerlichkeit, und zwar aus folgenden guten Gründen: Die Akamushi sind ganz ausserordentlich verbreitet, so dass fast alle Einwohner des Dorfes alljährlich erkranken, und zwar wiederholt. Keinem Einzigen ist es bekannt, dass jemals an der Stelle, wo eine Akamushi gebissen, sich eine Entzündung oder ein Geschwür entwickelt bätte. Meine sämmtlichen Patienten hatten schon früher an Akamushi gelitten, einer derselben gab ausdrücklich an, dass er einst über dreissig aus seiner Achselböhle herausgebolt habe. Diese Dinge seien völlig harmlos, sie werden überhaupt gar nicht als eigentlicbe Krankheit betrachtet, sondern gleich Flöhen einfach als lästige Plage angesehen. Ein Arzt, welcher die Akamusbi für die Krankheitsursache hielt (er selbst hatte freilich niemals die Entstehung eines Geschwürs aus einem Biss der Milbe entstehen sehen), verwies mich an einen Mann, der ihm drei Akamushi geschickt hatte. Dieser Mann aber gab an, er habe 5 Akamushi gehabt, drei habe er entfernt, zwei sitzen lassen, weil er nicht gut habe dazu gelangen können, es sei aber nichts weiter daraus entstanden. Ein 
Arzt zu Nishino führte mich zum Beweis des Zusammenhangs mit Milben zu einem schwer an Flussfieber Erkrankten; dieser aber und seine Verwandten stellten auf das Bestimmteste das Vorhandensein voll Akamushi an der Geschwürsstelle in Abrede. Der Hautschorf hatte sich bei ihm ohne sein Wissen gebildet und war erst durch absichtliches Suchen gefunden worden. Genau dasselbe wiederholte sich in Urasa. Der dortige Arzt galt für eine Autorität in dieser Frage, war aber der crasseste Ignorant, den man sich vorstellen kann. Für ihn war die Milbenäliologie ein Axiom, und er hatte offenbar sich nicht die geringste Mühe gegeben, selbst genau zu forschen. Er hätte sonst wohl wissen müssen, dass Akamushi häufig vorkommen, wo gar keine Tsutsugamushi beobachtet werden, was wenigstens allen Bauern in Kurodzu wohl bekannt war, und von jhnen gradezu als Beweis gegen die ldentität angefübrt wurde.

Diesen triftigen Gründen füge ich noch folgende bei:

In allen von uns beobachteten Fällen obne jegliche Ausnahme hatte sich die Hautnekrose, beziehentlich das Geschwür ohne die geringste Schmerzhaftigkeit, ja obne Wissen der Kranken entwickelt; stets war erst durch das Auftreten von Fieber und namentlich durch schmerzhafte Drüsenschwellung der Verdacht auf Mushi erweckt und ausdrücklich nach der kranken Hautstelle gesucht worden. Wenn es nun schon an und für sich unwabrscheinlich ist und allen unseren Erfahrungen widerspricht, dass der Biss oder gar das Einbohren irgend einer giftigen Milbe gerade an der Verletzungsstelle gar keine subjectiven Symptome hervorrufen sollte, so ist es vollends geradezu undenkbar, dass die Akamushi nur in den Fällen, wo eine schwere allgemeine Erkrankung folgt, keinen Schmerz machen sollten. In Urasa wird von einem Milbenfänger das Ausgraben der Milben systemalisch betrieben, und angeblich dadurch dem Ausbruch der Krankheit vorgebeugt. Aber ganz abgesehen von der Erfahrung, dass an einer Stelle, wo sich Akamushi fanden, niemals ein Geschwür entsteht, ist auch theoretisch das Ausgraben der Milben ein böchst zweifelhaftes Prophylacticum. Derin da die Milben erst nach 12-24 Stunden Jucken verursachen und bemerkt werden, so hätten sie wahrlich Zeit genug, den supponirten Giftstoff zu deponiren; ihre Entfernung wäre dann etwa ebenso wirksam, als die Tödtung einer Giftschlange, nachdem sie gebissen, oder einer Biene, nachdem sie gestochen hat. Andererseits haben wir niemals in der 
Wunde oder in ihrer Nähe eine Milbe finden können. Zwar hat Herr Kawakami im August 1877, als er beschäftigt war, den Schorf von einer Hautstelle abzunehmen, ein kleines weisses Pünktchen auf seinem Finger sich aufwärts bewegen sehen, das sich bei mikroskopischer Untersuchung als achtfüssige Milbe (viel grösser als Akamushi) darstellte, und er war geneigt, dieses Geschöpfchen mit der Aetiologie der Krankheit in Bezjehung zu bringen. Seit jeh aber dasselbe Thier auf meinem Tische, auf den Stühlen, in den Ritzen des Fussbodens meiner Wohnung in Kurodzu fand, während niemals jemand von uns oder den anderen Bewohuern erkrankte, musste der Gedanke natürlich fallen gelassen werden.

Es könnte scheinen, dass das Auftreten des Geschwürs an weichen, warmen und relativ geschützten Hautstellen dafür spreche, dass eine Milbe, ein Insect, das sich solche Stellen zur Einbohrung aussuche, die Ursache der Krankheit sei; ich glaube aber, dass dies durchaus nicht der Fall ist, dass vielmehr Scrotum und Achselhöhle durch ihre beständige Feuchtigkeit und durch die mehr oder weniger schmierige und klebrige Beschaffenheit ihres Secretes besonders befähigt sind, kleinste, mit der Luft aufsteigende Bestandtheile festzuhalten; dass sie also gewissermaassen der leimbestrichenen Fangplatte entsprechen, welche man für die Sammlung mancher Pilze an der Luft benutzt. Dabei ist es ja recht wohl möglich, dass das Gift nicht die unverletzte Haut durchdringt, sondern nur an aufgekratzten $u$. dgl. Stellen den Körper zu inficiren vermag. In diesem Sinne, indem sie eine kleine Verletzung der Haut machen und zum Kratzen Veranlassung geben, mögen die Akamushi zuweilen mit der Krankheit etwas zu thun haben.

Wie ferner nach dem Stich eines Insectes oder einer Milbe eine 6 tägige Incubationszeit bestehen soll, ehe die ersten localen Symptome auftreten, wäre wohl auch kaum verständlich.

Dass es sich nicht um mechanische Reizung durch Deponirung von Eiern u. dgl. handelt, das beweist ausser dem Fehlen aller localen Entzündungserscheinungen vor allem die mikroskopische Untersuchung. Ich habe oft den primären, noch ganz unberührten Hautschorf abgenommen, und auf jede Weise mit und ohne Reagentien untersucht, habe aber nie etwas finden können, was irgendwie auf Zusammenhang mit Milben oder anderen lebenden Geschöpfen hingewiesen hätte. Doch kann ich nicht umhin, die auffallende That- 
sache zu erwähnen, dass in der zweiten Hälfte des August 1877 die Zahl der Fälle von Flussfieber und Akamushi gleichzeitig rasch abnahm. Der Grund dafür war wobl der, dass die enormen Regengüsse, welche Ende Juli und Anfang August eine zweite grosse Uebersebwemmung im Shinanogawathal berbeiführten, die Milben grossentheils tödteten und zugleich den Krankheitsstoff auf eine sofort $\mathrm{zu}$ besprechende Weise unschädlich machten.

Wäre wirklich eine Milbe die Ursache der Krankheil, so müsste diese durch die Pferde, durch die Menschen, durch Kleider, Betten und andere Gegenstände häufig auf die übrigen Familienglieder, Hausbewohner, Nachbarn übertragen werden, welche direct mit dem Ueberschwemmungsgebiete nichts zu thun haben. Das ist aber entschieden nicht der Fall. Auch in die benachbarten Dörfer müsste das Leiden auf diese Weise verschleppt werden. Auch das kommt nicht vor. Die Aerzte, welche so energisch für die Milbentheorie eintraten, hatten sich diese naheliegenden Fragen gar nicht gestellt und waren ganz verdutzt, als sie aufgefordert wurden, diese Thatsachen mit ihrer Hypothese za erklären.

Nachdem somit die übrigens erst in den letzten Jahren aus Erklärungsbedürfuiss mit Gewalt in die Sache hineingetragene Milbentheorie als unwahrscheinlich erscheint, bleibt noch eine andere Erklärung, die sehr plausibel ist und offenbar mit den Thatsachen besser harmonirt. Dies ist die Auffassung des Flussfiebers als einer miasmatischen Infectionskrankheit. Es steht als solche dem Wechselfieber am nächsten, sein Gift unterscheidet sich aber von dem Malariamiasma durch geringere Flüchtigkeit und durch zeitlich beschränktere Wirksamkeit. Es erfordert zu seiner vollen Entwickelung einen hohen Hitzegrad und ein Zusammentreffen von Umständen, wie es sich auch im Sommer nur an gewissen Orten zeigt.

Die Erfahrung lehrt, wie schon früher angeführt, dass fast nur die Leute, welche den Hanf schneiden, erkranken, nicht aber, oder doch höchst selten die Schiffzieher. Erstere stehen den ganzen Tag gebückt und setzen ihren Körper den aus dem umgebrochenen Boden aufsteigenden Dünsten aus; letztere hingegen gehen stets unmittelbar am Wasser, und zwar an Orten, wo meist viel frisch aufgeworfenes Land und wenig Humus sich befindet. Das ist aber von grosser Bedeutung in der Aetiologie der Krankheit. Die Einwohner haben längst bemerkt, dass im ersten und zweiten Jahre, so lange 
noch wenig Pflanzen darauf wachsen und nicht cultivirt wird, aufgeschwemmtes Land relativ ungefährlich ist, und ebenso dass Stellen, die lange Zeit in Cultur stehen und gründlich bebaut wurden, ihre Gefäbrlichkeit verlieren, so regelmässig auch, nach wie vor, Ueberschwemmungen darüber hinweggehen. In den ersten par Jahren wächst auf dem Sande nur Schilf, allmäblich kommen Bambusgras und verschiedene krautarlige Pflanzen, die bei ihrem Zerfall den Boden düngen und die Grundlage für Humus abgeben. Jetzt wird, zu einer Zeit, wo der Boden noch immer sehr porös und für Gase leicht durchgängig ist, mit der Cultur begonnen, und von dieser Zeit des Umgrabens des Bodens an erscheint die Krankheit. Je länger cultivirt wird, um so dicker wird natürlich die eigentliche Humusschicht, um so mehr wird durch den regelmässigen Pflanzenwuchs der Miasmaentwickelung vorgebeugt, und sobald das Alluvium auf diese Weise gewöhnlichem Culturboden gleich geworden ist, hört man nichts mehr von Flussfieber. - Das Gift ist aber transportabel, wenn auch in sehr beschränktem Maasse: es kann durch die Frucht, den Hanf u. dgl. übertragen werden, möglicherweise durch hängenbleibende Erdstileke, wie aus den Fällen hervorgeht, in welchen die Patienten sich niemals auf dem Alluvium selbst bewegt hatten. $0 \mathrm{~b}$ das berechtigt, die Krankheit als miasmatisch-contagiös zu bezeichnen, lasse ich dahingestellt. Das allein aber genügt nicht, um alles zu erklären. Warum entsteht nicht einfach Malaria? Warum entsteht gerade diese specifische Krankheit, und warum entsteht sie nur bier, während doch an so vielen anderen Orten die bisher beschriebenen Bedingungen ebenso gegeben sind? Es muss noch eine andere specifische locale Ursache vorhanden sein, wenn Flussfieber entstehen soll. Worin nun aber diese specifische Ursache besteht, das ist ebenso unbekannt, als das eigentliche Gift des Wechselfiebers, des Typhus, der Cholera. Dass es sich um ein Miasma vivum - oder anders ausgedrückt, um ein Inficiens vivum - handelt, ist in unserem Falle mindestens ebenso wahrscheinlich, als bei jenen Krankheiten, ja gerade das Auftreten einer Art Verletzung als erstes Symptom war es ja und ist es noch, das stets wieder den Gedanken an ein Inficiens im gröberen Sinne erweckt. Aber gesehen worden ist ein solcher besonderer Organismus nie. Bei der aufmerbsamsten Untersuchung habe ich niemals Bakterien im Blute 
gefunden und selbst im primären Schorfe waren sie auch nicht entfernt zahlreich genug, als dass man sie, wie bei Diphtherie, bei Milzbrand für die Ursache des ganzen Krankheitsprozesses ansehen könnte. Dennoch ist diese Frage noch nicht als völlig erledigt zu betrachten. Denn erstens habe jch nur in acht Fällen das Blut untersuchen können, und dann ist vielleicht die angewandte Vergrösserung (600) noch nicht genügend stark. Auch war die Erwärmung des Objecttisches unvollkommen, und namentlich war es schwer, ihn auf einer bestimmten Temperaturhöbe $\left(40-41^{\circ}\right.$, der Blutwärme der Kranken entsprechend) zu erhalten. Um aber nicht durch Ueberbitzung des Blutes Zerfall der rothen Blutkörperchen und Pseudomikrokythämie ${ }^{1}$ ) herbeizuführen, wurde die Temperatur absichtlich etwas niederer gewählt. Wenn also die etwaigen Organismen nur bei einer gewissen Höhe der Temperatur sichtbar sein sollten, so könnten sie meiner Aufmerksamkeit möglicherweise entgangen sein.

Der Beweis, dass die Krankheit nicht contagiös ist, ist leicht. Es braucht nur auf die oben bereits angeführten Thatsachen bingewiesen zu werden, dass die Krankheit nicht von einem Familienglied auf das andere übertragen wird und dass sie trotz eines ziemlich lebhaften Verkehrs auf ganz umschriebene Bezirke beschränkt bleibt. Zwar ist es durchaus nicht selten, dass Vater und Sohn oder zwei Bruder erkranken, aber dann haben sie sich beide der Infection ausgesetzt. Auch wird berichtet, dass alle paar Jahre einmal der Fall vorkommt, dass fremde Leute, welche zur Zeit der Ernte die Nähe der gefährlichen Stellen einfach passiren, erkranken. Auch das ist aus dem Gesagten leicht verständlich. Das Gift ist ja einigermaassen transportabel; man kann durch Beschäftigung mit der Frucht allein erkranken. Aber diese Transportabilität ist äusserst beschränkt, die Frucht, das directe Product des Bodens, dient nur als Träger, aber nicht als Reproducent; wer an der von dem Infectionsheerde gebrachten Frucht vorbeigeht, bleibt gesund, wer sie sondert, reinigt,

1) Mebrere veröffentlichte Fälle von acut entstandener und ebenso plötzlich wieder verschwundener Mykrolythämie sind gewiss auf diese Weise entstanden, wie mich meine früheren Erfahrungen äber Blutuntersuchungen schliessen lassen. Nichts ist leichter, als durch allmähliche Erwärmung des 0bjecttisches eine Theilung der rothen Blutkörperchen ad oculos zu demonstriren. Es ist fast komisch zu sehen, mit welcher Verwunderung die Verfasser vor diesen Artefacten ihrer eigenen forscherischen Thätigkeit stehen und mit welchem Ernst sie ihren räthselhaften Fund discutiren. 
wer, so zu sagen, innerhalb derselben steht, ka n n erkranken, muss es aber nicht. Selbst wenn in Häusern, deren Familienglieder häufig erkranken, auch solche afficirt würden, welche niemals direct sich der Infection am Ufer oder durch Beschäftigung mit dem Hanf ausgesetzt hatten, - was aber nicht der Fall ist, - wäre dies doch noch kein Beweis für Contagiosität. Auch Typhus abdominalis und Cholera befallen viele Leute in e inem Hause, sind aber beide nicht direct contagiös.

Impfbarkeit. Versuche, die Krankheit durch Impfung auf Katzen und Kaninchen zu übertragen, waren ausnahmslos obne Erfolg. Es wurden zur Impfung verwendet das Blut der Kranken, der mit Glycerin verriebene Schorf und Eiter aus dem Geschwürsgrunde. Selbst an der Impfstelle wurde keine irgend wesentliche Reaction bemerkt. Versuche an Menschen anzustellen, hielten wir uns nicht berechtigt, um so weniger, als selbst erfolgreiche Impfung keinen Schutz gegen weitere Erkrankung bieten würde.

Denn mehrmalige Erkrankung ist nicht selten. Unter 25 Fällen waren 2 zum zweiten Mal, einer zum dritten Mal erkrankt. Ausserdem sah ich mehrere Leute, welche im Laufe früherer Jahre wiederholt an Flussfieber gelitten hatten. Bald lagen zwischen den Erkrankungen nur wenige Jahre, bald Jahrzehnte. Im Allgemeinen gilt die Regel, dass die folgenden Erkrankungen leichter sind, als die erste, doch giebt es auch hier Ausuahmen.

Alter und Geschlecht sind ohne Einfluss. Wenn Männer häufiger erkranken, als Frauen oder Kinder, so liegt das einfach daran, dass sie sich häufiger der Infection aussetzen, als diese. Unter unseren 25 Fällen waren 3 Kinder, das jüngte 6 Jahre alt, und 6 Frauen. Die Krankheit verlief bei Männern und Frauen ganz gleich, ohne Unterschied in der Prognose.

\section{Epikrise.}

Die Bezeichnung der uns beschäftigenden Krankheit als Flussoder Ueberschwemmungsfieber bedarf wohl nach dem Vorhergehenden keiner weiteren Rechtfertigung; Ueberschwemmungsfieber ist vielleicht der richtigere Name, weil nicht der Fluss als solcher, sondern nur, insoweit er das Land überschwemmt, als ein Hauptfactor betheiligt ist. Welcher Art der andere Factor ist, die Noxe, welche unter Mitwirkung des Wassers den Körper krank macht, bleibt dabei eine ganz offene Frage. 
Stellung der Krankheit im nosologischen System.

Soweit wir auch heutzutage entfernt sind von einer Classification der Krankheiten nach Art botanischer und zoologischer Sebemata, so sehen wir uns doch genöthigt, im Interesse der Ordnung und Uebersicht jeder Krankheit einen bestimmten Platz im weiten Felde der speciellen Pathologie anzuweisen, und wir stellen sie mit denjenigen anderen Krankheiten zusammen, mit welchen sie wesentliche Züge oder den Sitz gemein hat. In der Regel wird dabei das organographische Princip benutzt, weil dieselbe Krankbeit, in verschiedenen Organen auftretend, ganz verschiedene Symptome hervorruft. Wir besprechen also in den Lehrbüchern den Krebs der Mamma und des Magens nicht gemeinschaftlich, sondern getrennt bei den einzelnen Organen. Nur in einem Falle verlassen wir diesen Eintheilungsmodus: bei den Infectionskrankheiten. Sie mögen noch so deutlich localisirt sein, wie z. B. Masern, Pocken, Varicellen, wir handeln sie nicht bei dem einzelnen Organe ab (nur einige wenige Dermatologen ziehen die erwähnten Krankheiten in den Bereich ihrer Besprechung), sondern fassen sie, grundverschieden wie sie sind, nach einem einheitlichen Gesichtspunkte, dem ätiologischen, in eine grosse Gruppe zusammen. Da nun kein Zweifel darüber bestehen kann, dass wir es in unserem Falle mit einer durch eine specifische Ursache hervorgerufenen Krankheit zu thun haben, so wenden wir auf das Ueberschwemmungsfieber dasselbe ätiologische Princip an und stellen es zu den Infectionskrankheiten.

Dass es hier in Betreff seiner Entstehung der Malaria verwandt ist, ist schon oben erwähnt. Dagegen zeigen die Symptome in mancher Hinsicht Anklänge an andere Infectionskrankheiten. Man könnte versucht sein, die Krankbeit zu den acuten Exanthemen zu stellen; denn in beiden Fällen ist ein Prodromalfieber vorhanden, und dann folgt ein über den ganzen Körper verbreitetes Exanthem. Aber es bildet beim Flussfieber der Haulausschlag nicht das auffälligste Symptom; im Gegentheil, in leichten Fällen ist davon fast gar nichts zu bemerken, während andere Erscheinungen, die Geschwürsbildung und die Drüsenschwellung in voller Deutlichkeit vorhanden sind. Grössere Aehnlichkeit besteht entschieden in Bezug auf das allmähliche Ansteigen und die lange Dauer des Fiebers, den Ausbruch des Exanthems erst am Ende der ersten Woche, 
die Milzschwellung, mit Abdominaltyphus, ja die Erkrankung der Lymphdrüsen in der Nähe der primären Localisation macht die Analogie so gross, dass man sich versucht fühlen könnte, die Krankheit im Gegensatz zu Abdominaltyphus als Typhus cutaneus oder superficialis zu bezeichnen. Aber andererseits fehlt ja gerade der benommene, halb bewusstlose Zustand, welcher dem Typhus den Namen gegeben hat.

Der Schorf, seine Farbe u.s. w. haben wohl am meisten Aehnlichkeit mit einer vertrockneten hämorrhagischen Pocke oder einer Milzbrandpustel. Auch bei dieser bildet sich, und zwar sicher an der Eintrittsstelle des Giftes, ein schwarzer nekrotischer Fleck, oder vielmehr eine Pustel, die zu localer Nekrose führt. Sollen wir deshalb annehmen, dass auch beim Flussfieber der Eintritt des Giftes an jener Stelle stattfindet, dass also wirklich eine Art Impfung Statt hat? Möglich, sogar recht wahrscheinlich, wenn man in Betracht zieht, dass die Lymphdrüsenaffection zuerst in der Nähe jener Stelle localisirt ist, und von da, allmählich schwächer werdend, nach der Peripherie weiter schreitet, und dass in ganz leichten Fällen die Schwellung und Schmerzhaftigkeit geradezu auf jene Drüsen beschränkt bleibt. Eben solche Fälle sprechen für die Ansicht, dass die Lymphdrüsen als eine Art Filter für schädliche Bestandtheile angesehen werden können und müssen. Es ist ja ganz zweifellos und die tägliche Erfahrung beweist es stets auf's Neue, dass Lymphdrüsen z. B. der Ausgang für fatale Tuberculose werden kőnnen, dass sie als Depot und Bildungsstätten für schädliche Stoffe dienen, nachdem der übrige Körper längst gesund ist, dass sie also eine stete Gefabr für ibren Besitzer mit sich bringen. Andererseits lehrt dieselbe tägliche Erfahrung, dass in vielen acuten Entzündungen, und zwar meist schlimmer Art, z. B. nach Leicheninfection, die geschwollenen Drüsen die Grenze bezeichnen, bis zu weleber eine sofortige directe Verbreitung des Giftes stattgefunden hat; durch seine Einwirkung schwellen die Drüsen an, entzïnden sich und durch die Entzündung wird die Circulation der Lymphe erschwert, beziehentlich unterbrochen und dadurch einer raschen Weiterverbreitung vorgebeugt. Läge die Lymphdrüse mil ihren gewundenen und complicirten Wegen nicht dazwischen, so würde das Gift, einmal in die Lymphbahn aufgenommen, sofort über das ganze Blutsystem vertheilt; es müsste dann, bei der supponirten Vermehrungsfähigkeit 
der betreffenden Parasiten, stets den ganzen Organismus krank machen. Der letztere erkrankt auch wirklich bei den schweren Infectionen mit Milzbrand- und Leichengift, wenn die Lymphdrüsen nicht im Stande sind, alles zurückzuhalten; leichtere Fälle dagegen können ganz local verlaufen. Genau so steht es mit dem Flussfieber. In zwei ganz leichten Fällen mit deutlich entwickeltem Geschwür fand ich nur die ganz zunächst liegenden Drüsen afficirt, und in beiden Fällen waren so gut wie keine Allgemeinerscheinungen eingetreten. Wenn aber in diesen Beziehungen Aehnlichkeit mit Milzbrand besteht, so sind audererseits auch die Unterschiede bedeutend. Beim Milzbrand finden wjr zunächst eine zweifellose Entzündung, ein Bläschen, eine Pustel auf stark gerötheter, schmerzhafter Basis und eine, oft über ein ganzes Glied verbreitete Anschwellung, - alles Symptome Jocaler Reizung, wie sie durch den giftigen Parasiten, den Bacillus anthracis hervorgebracht werden. Von dem Allem ist beim Flussfieber keine Rede. Hier entsteht ohne jegliche subjective und fast ohne alle merkliche objective Veränderung eine ganz kleine schwarze Stelle, die zu einem Geschwür führt; der gesammte kranke Bezirk hat kaum je mehr als $2 \mathrm{Cm}$. Durchmesser. Keine Reizung, keine Induration, keine Schwellung, kein Schmerz, keine Neigung zum Fortschreiten. Sollten wirklich Bakterien dabei vorhanden sein, so sind sie sicher weit kleiner und schwerer zu erkennen, als der mir von früheren Untersuchungen her wohlbekannte Milzbrandpilz. Dieses völlige Fehlen der localen Reizerscheinungen, der Mangel jeder Functionsstörung des betroffenen Gliedes machen es wabrscheinlich, dass das Gift in diesem Falle nicht erst eine Entzindung und dann eine secundäre Nekrose erzeugt, sondern dass es direct localen Gewebstod hervorruft. Der gesammte Ablauf der Symptome rechtfertigt diese Auffassung, welche ja in neuerer Zeit aucb auf die Pocken übertragen worden ist, obwobl bier die Verbältnisse weniger in die Augen springend daliegen. Der schlaffe, träge Eiterungsprozess beim Flussfieber ist als ein Demarcationsvorgang zu betrachten. Je nachdem dabei das Gift in grösserer oder geringerer Menge in die eröffneten oder durch Krankheit abnorm durchlässig gewordenen Capillaren eindringt, je nachdem das Individuum für die Fortpflanzung und Vermehrung desselben disponirt ist oder nicht, erfolgt bald eine mebr allgemeine, bald eine localisirte Erkrankung.

Eine andere Krankheit, mit der das Flussfieber durch die 
Schorfbildnng Analogie bietet, ist die Diphtherie, aber für diese gilt fast Alles, was über Milzbrand gesagt ist; am primären Heerde sind die Reizungserscheinungen sehr deutlich, die Entzündung, der Schmerz sehr quälend; ausserdem zeigt das Geschwür, das nach Abstossung des Schorfes bleibt, ein schlechtes, ungesundes Aussehen, es hat eine Neigung, in der Umgebung weiter zu fressen.

Die beim Flussfieber beobachtete allgemeine Hyperästhesie und die Empfindlichkeit der Muskeln gegen Druck, das Wimmern und der öfter vorkommende Urindrang erinnern an das Verhalten bei Cerebrospinalmeningitis, mit der aber sonst gar keine Aehnlichkeit vorliegt.

Aus dem Gesagten geht hervor, dass unsere Krankheit, wenn sie auch in einzelnen Symptomen Aehnlichkeit mit anderen Krankheiten hat, doch mit keiner derselben identisch jst, oder sich an sie besonders nabe anschliesst, dass sie vielmehr bis jetzt nicht bekannt war und durch die Art und Reihenfolge der Erscbeinungen isolirt steht.

Das Hauptinteresse der Krankheit liegt aber nicht blos in der Vermehrung der langen Ketle der gekannten Leiden des Menschengeschlechts um ein neues Glied, sondern es liegt wesentlich darin, dass die Ansicht, nach welcher die Localisation im Darme bei Typhus, im Rachen bei Diphtherie eine Folge der directen Einwirkung des Giftes ist, nach welcher diese Krankheiten also zuerst local sind und erst nachher allgemein werden, - dass diese Anschauung durch das Verbalten beim Flussfieber, bei dem wir an der Oberfläche beobachten, eine wesentliche Stütze erhält. Gelänge es, die Wahrscheinlichkeit, dass hier ein parasitisches Gift in den Körper eintritt, zur Gewissheit zu erbeben, - und die Aussicht dazu ist bei genauer Ueberlegung eine relativ grosse, - so wäre damit ein wichtiger Schritt in der Lehre von den Infectionskrankheiten gethan, ein Schritt, nicht blos von theoretiscber Bedeutung für den alten Streit über die Art und Weise des Krankwerdens, sondern auch von Wichtigkeit für eine rationelle Prophylaxis. Auch der z. B. bei Cbolera auf den Ausbruch der Affection so offenbare Einfluss einer leichten Erkrankung, eines Darmkatarrhs, würde dadurch dem Verständniss näher gerückt. Ich werde mich bestreben, bei Gelegenheit weiterer Forschungen diesem Gegenstande meine besondere Aufmerksamkeit zuzuwenden. 
Therapie.

Ueber die Therapie habe ich wenig zu sagen. Die Fälle, welche in unserer Behandlung standen, sind genesen. Mehrere Kranke ausserbalb des Hospitals sind gestorben; zwei davon waren, als wir sie zuerst sahen, in einem Zustande, in dem keine Arznei mehr helfen kann. $O b$ eine frühzeitige Behandlung sie gerettet hätte, darüber lässt sich natürlich kaum eine Vermuthung aussprechen; im Allgemeinen verpflichten uns unsere Erfahrungen trotz aller Fortschritte in der Therapie zu grosser Vorsicht in der Beurtheilung unserer Leistungen bei acuten Infectionskrankheiten. Der Mensch ist aus natürlicher Schwäche nur allzusehr geneigt, eine erwünschte Veränderung auf seinen Einfluss zurückzuführen, wenn er nur seinen Einfluss in dieser Richtung versucht hat; und gerade der Arzt ist besonders leicht in Gefahr, in diese Schwäche zu verfallen.

Von den angewendeten Mitteln batte Natron salicylicum selbst in kleinen Dosen stets auf das Fieber eine deutliche objective und gewöhnlich auch eine gute subjective Wirkung, doch ist die Zahl der so behandelten Fälle viel zu klein, um irgend allgemeine Schlüsse zu erlauben. Chinin schien weniger gut zu wirken; es kam seltener zur Verwendung, weil ich caeteris paribus der Salicylsäure den Vorzug gebe. Uebrigens ist es zweifelhaft, ob in den meisten Fällen überhạupt Antipyretica nothwendig sind.

Sonst wurden, ausser gelegentichen Dosen von Narcoticis gegen Schlaflosigkeit, Schmerz oder Husten, fast nur Abführmittel (Calomel, Carlsbader Salz) oder Klystiere verordnet und diese batten durch ihre Wirkung stets grosse Erleichterung zur Folge.

Wenn die Vermuthung richtig ist, dass das Haften des Giftes durch die Benetzung der Haut mit klebrigem Secret befördert wird, so wäre eine sehr einfache Prophylaxis für den Einzelnen darin gegeben, dass er, wäbrend er die gefürchtete Gegend besucht (also eine oder höchstens zwei Wochen lang) sich mehrmals täglich badet und gründlich wäscht. Wenn nicht in allen, würde doch dadurch in vielen Fällen einer Infection vorgebeugt werden können. Durch vollständige Bekleidung allein wäre nichts $z u$ erreichen, denn eine eng anschliessende, den Körper ganz verhüllende Kleidung würden die Leute niemals tragen, und andererseits, sobald ein Luftstrom zwischen Haut und Kleid circulirt, wird letzteres, weil es die Ansammlung der Secrete begünstigt, geradezu schädlich wirken können. 
Von weit grösserer Bedeutung aber und dabei gar nicht schwer auszuführen, sind allgemeine hygieinische Maassregeln, welche die der Entwicklung des Giftes günstigen Bedingungen vernichten. Als solche Maassregel empfiehlt sich vor allem eine rasche Cultivirung des Bodens mit Pflanzen, welche erfahrungsgemäss einen salutären Einfluss auf schlechtes Land besitzen. Hier ist in erster Linie zu erwăhnen der Eucalyptusbaum, welcher in jener Gegend ohne allen Zweifel wohl gedeihen wird; wenigstens kommen die Exemplare, die in Tokio gepflanzt oder aus Samen gezogen werden, gut fort, obwohl sie nicht die fast fabelhafte Schnelligkeit des Wachsthums zeigen, welche in anderen Ländern diesem Baume nachgerühmt wird.

Indessen ist es schwerlich nöthig, zu dem exotischen Eucalyptus zu greifen, denn Japan selbst besitzt einen Baum, welcher alle erforderlichen Ejgenscbaften in hervorragendem Maasse besitzt, die Paulownia imperialis, japanisch Kiri no ki. Der Baum ist auch in Europa in kurzer Zeit allgemein bekannt und beliebt geworden und bedarf daher keiner näheren Beschreibung. Sein Wachsthum ist ganz ungewöhnlich rasch und seine Riesenblätter sind energische Absorptionsorgane. Ich habe im Tempelhof in Kurodzu ein Exemplar gemessen, das in einem Sommer (von April bis August) 15 Fuss boch geworden war. Der Stamm hatte unten $24 \mathrm{Cm}$. Umfang und mehrere Blätter über 1 Meter Durchmesser. Es dürfte sich daher, um den Boden zu consolidiren und zu reinigen, schwerlich eine vorzüglichere Pflanze finden lassen, als dieser Baum. Man hat in Europa vielfach Samenblumen gepflanzt, um Malariaorte gesund zu machen. Alle Eigenschaften des Helianthus besitzt die Paulownia in weit höherem Grade und sie dürtte sich daher in Europa für Stelien, wo Eucalyptus nicht mehr fortkommt, dringend empfehlen; sie hat in öconomischer Hinsicht auch noch den Nutzen, ein werthvolles Holz zu liefern.

Ich habe diese Vorschläge betreffs individueller und allgemeiner Prophylaxe dem Gouverneur der betreffenden Provinz übermittelt und hoffe später über den Erfolg berichten zu können. 